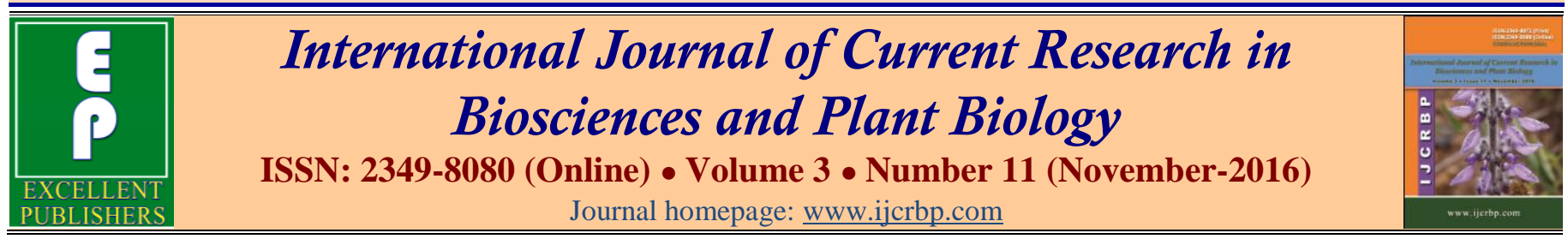

Original Research Article

doi: http://dx.doi.org/10.20546/ijcrbp.2016.311.014

\title{
Prediction of G Protein Coupled Receptors from Plant Genomes
}

\author{
Deisy Xavier Amora ${ }^{1}$, Emmanuel Bresso ${ }^{1}$, Roberto Coiti Togawa ${ }^{1}$, Priscila Grynberg ${ }^{1}$, \\ Bernard Maigret ${ }^{2}$ and Natália Florêncio Martins ${ }^{1 *}$
}

${ }^{1}$ EMBRAPA Recursos Genéticos e Biotecnologia, Parque Estação Biológica, Brasília, DF, Brazil

${ }^{2}$ CNRS, LORIA, UMR 7503, Lorraine University, Vandoeuvre-lès-Nancy, France

*Corresponding author - natalia.martins@embrapa.br

\begin{abstract}
A b st r a ct
G-protein coupled receptors (GPCRs) are the largest family of membrane proteins, as key components of signal transduction pathways. Despite the current knowledge, GPCRs in plants are not well characterized if compared with animals and are still a matter of controversy. The availability of plant genomes allows the prediction and characterization of diverse GPCRs, as for several species the repertoire of GPCRs remains unclear. As a contribution to this problem, we present the in silico analyses of putative GPCRs candidates from Arabidopsis thaliana, Capsicum annuит, Glycine max, Manihot esculenta, Medicago truncatula, Oryza sativa, Phaseolus vulgaris, Populus trichocarpa, Ricinus communis, Solanum lycopersicum, Solanum tuberosum, Sorghum bicolor, Theobroma cacao, Triticum aestivum, Vitis vinifera and Zea mays proteomes. From a total of 997,435 proteins collected, the sequences were selected by length, reducing the initial collection to 487,012. GPCRpipe program predicted 60 GPCRs candidates, ranging from none (Capsicum аппиит) to 12 candidates (Populus trichocarpa) (median $=3 \pm 2.90$ ). The Neighbor joining dendrogram of the 60 predicted GPCR candidates grouped the proteins in three clades. These findings may indicate that GPCR in plants are involved in drought stress responses.
\end{abstract}

\section{Introduction}

G-protein coupled receptors (GPCRs) belong to the largest family of membrane proteins as key components of signal transduction pathways. They are activated by diverse ligands, including odorants, fatty acids, peptides and neurotransmitters, across cell membranes. GPCRs are responsible for the communication between cell and environment through GPCRs signaling. Although GPCRs are important to pharmaceutical application, very few is known about plant GPCRs. Usually, the identification of novel GPCRs from genome analysis allowed the prediction of new important receptors in

\section{Article Info}

Accepted: 01 November 2016

Available Online: 06 November 2016

\section{Ke y words}

G protein coupled receptors

Membrane protein

Protein prediction

Signal transduction 
was isolated by Josefsson and Rask (1997) and PlakidouDymock et al. (1998) which concluded that GCR1 encodes the first 7TM receptor homologue identified in higher plants and is involved in cytokinin signal transduction. In the last decade, the physiological effect of GCR1 has been investigated and several studies put together information about the seed germination, the interaction with cell signaling mediators, add to the response to brassinosteroids and gibberellins, as well as reducing drought stress (Chakraborty et al., 2015b). The genome mining of Arabidopsis described a computational strategy that identified $54 \quad 7 \mathrm{TMpR}$ candidates but only one as GCR1 (Moriyama et al., 2006). Recently, Chakraborty et al. (2015a) provided experimental validation for the physiological role of GCR1 in which an extensive genome wide response of unknown genes and processes has been suggested. Moreover, the authors pointed to the need of continue studying the role of GCR1 in cell signaling in Arabidopsis, including considering the contest to writeoff plant GPCRs, or their role in plant G-protein signaling. From the three putative GPCRs in Arabidopsis only one, GCR1, shows marked homology with GPCRs (Assmann, 2002). From Dictyostelium, one cAMP receptor CAR1 has 20 to $23 \%$ identity with the CARs.
The Medicago RGS-protein homolog shares $60 \%$ sequence identity (Temple and Jones, 2007).

The availability of several plant genomes made possible the prediction and characterization of diverse GPCRs as well as a comparative analysis of the GPCR structurefunction relationship in plants. Gookin and coworkers (2008) performed a whole proteome survey for GPCRs in three plant genomes, namely Arabidopsis, poplar and rice. The authors used experiments binding tests with GPA1 and showed through G-protein coupled receptor classification and molecular evolutionary analyses that both individual G-protein coupled receptor candidates and candidate G-protein coupled receptor families are conserved among plant species. We have extended this work and in the present paper we describe the comparative survey for GPCRs in sixteen plant genomes. We expect that this paper will contribute to solve this debate and increase knowledge in plant GPCR candidates.

\section{Materials and methods}

The sixteen proteomes used for detecting GPCRs were downloaded from several database repositories, as described on Table 1.

Table 1. Dataset sources and versions used for GPCR detection.

\begin{tabular}{lll}
\hline Organism & Source & Version (Reference) \\
\hline Arabidopsis thaliana & TAIR: The Arabidopsis Information Resource & 10.29 (Lamesch et al., 2012) \\
Capsicum annuum & Solgenomics & 1.55 (Kim et al., 2014) \\
Glycine max & Phytozome & 1.1 (Schmutz et al., 2010) \\
Manihot esculenta & Phytozome & 6.1 (Prochnik et al., 2012) \\
Oryza sativa & Phytozome & 7.0 (Ouyang et al., 2007) \\
Phaseolus vulgaris & Phytozome & 1.0 (Schmutz et al., 2014) \\
Solanum lycopersicum & Solgenomics & 2.4 (Sato et al., 2012) \\
Solanum tuberosum & Solgenomics & 3.4 (Xu et al., 2011) \\
Triticum aestivum & Phytozome & 2.2 (Mayer et al., 2014) \\
Zea mays & EnsemblPlant & AGPv3.26 (Schnable et al., 2009) \\
Vitis vinifera & Phytozome & Genoscope.12X (Jaillon et al., 2007) \\
Theobroma cacao & Phytozome & 1.1 (Motamayor et al., 2013) \\
Sorghum bicolor & Phytozome & 3.1 (Not published) \\
Ricinus communis & Phytozome & 0.1 (Chan et al., 2010) \\
Populus trichocarpa & Phytozome & 3.0 (Tuskan et al., 2006) \\
Medicago truncatula & Phytozome & 4.0 (Young et al., 2011) \\
\hline
\end{tabular}

\section{GPCR identification}

To identify candidate GPCRs we performed a bioinformatic analyses concatenated as described in Fig. 1 where several softwares were used to predict protein topology and to classify putative GPCRs. Each proteome set was analyzed independently. The first step consisted to filter all the proteins according to their size. As the large majority of GPCRs contains between 250 and 1000 residues, the selected proteins by our pipeline were the ones within this range. The second step was to submit the selected proteins to the 
Transmembrane helix predictors in order to identify proteins with TM regions (Krogh et al., 2001). The third step was the prediction of GPCRs through GPCRpipe program (Theodoropoulou et al., 2013). Two methods in GPCR pipe were used for the detection of GPCR: 1) Based on Hidden Markov Model, where the first step was designed for the detection of GPCR. 2) Using a library of domains consisting in 39 Pfam profile HMMs (specific to different families of GPCR). We used the GPCRpipe "AND" method, meaning that a GPCR was predicted only if there was a consensus between the two methods to confirm the prediction. This choice resulted in a small number of GPCR candidates but, on the other hand, limited the number of false positive predictions. The final step was the validation of GPCRpipe candidate predictions, through the protein domain prediction with ProDom (Corpet et al., 2000). Only proteins annotated with a GPCR domain were finally considered as putative GPCR candidate.

\section{Transmembrane helix predictions}

Five programs were used to predict transmembrane helices. Topology prediction was performed on each selected proteome by analyzing the complete sequences with TMHMM version 2.0 (Krogh et al., 2001), Phobius (Käll et al., 2007), HMMTOP2 (Tusnády and Simon, 2001), MemBrain (Shen and Chou, 2008) and Octopus (Viklund and Elofsson, 2008).

\section{GPCR classification}

The candidate proteins were grouped based on the sequence similarity and class recognition through CLUSTALW alignment (Higgins and Sharp, 1998). The phylogenetic tree of the GPCR candidates was built by Mega 6.0 using Neighbor-joining method and 10,000 repetitions. In parallel, the sequence of each GPCR candidate was submitted to two web servers: PCA-GPCR (Peng et al., 2010) and GPCRPred (Bhasin and Raghava, 2004) dedicated to GPCR class recognition. Each of these prediction methods provides the GPCR class and its subfamily. The transmembrane helices were aligned using TM-Coffee (Chang et al., 2012).

\section{Gene ontology and domain identification}

The functional analysis (GO) of the proteins was predicted using AgBase 2.0, a curated resource for agricultural plant gene products (McCarthy et al., 2011). For GO annotation, the protein sequences were submitted to Goanna, using as database the AgBase-
UniProt. All the evidence codes were selected and the others parameters were set as standard. The summarized results retrieved from Goanna (slim input) were submitted to GoSlim Viewer (McCarthy et al., 2006). The redundant GO terms were removed by REVIGO (Supek et al., 2011). For domain identification, the sequences were submitted to InterProScan (Jones et al., 2014). The prediction of the presence and location of signal peptide cleavage sites in amino acid sequences was done with SignalP (SignalP 4.0 - Discrimination between Signal Peptides and Transmembrane Regions).

\section{Results}

In order to explore the GPCR repertoire in plant genomes, we selected data from different sources and taxonomic families, i.e., Solanaceae, Malvaceae, Oryzeae, Triticeae, Fabaceae, Vitaceae, Euphorbiaceae, Flacourtiaceae and Poaceae. Following the pipeline described in Fig. 1, the 997,435 proteins from the sixteen selected plants were filtered by length (proteins between 250 and 1000 amino acids) resulting in 487,012 candidates. To reduce the number of proteins to be submitted to GPCRpipe, only proteins with seven transmembrane helices (7TM) were retained. This resulted in 4,878 proteins which were submitted to the GPCRpipe program. The bioinformatic analysis predicted a total amount of 60 GPCRs (Tables 2 and 3). The number of candidates reflects the stringency of the methods, as for Arabidopsis, p.e., our system predicted the 5 putative GPCRs, already known (Yadav and Tuteja, 2011). For Populus, Medicago and rice the results were lower than predicted previously by Gookin et al. (2008), Chen and Ellis (2008) and Taddese et al. (2014). While for other species the number of GPCR candidates is a novelty.

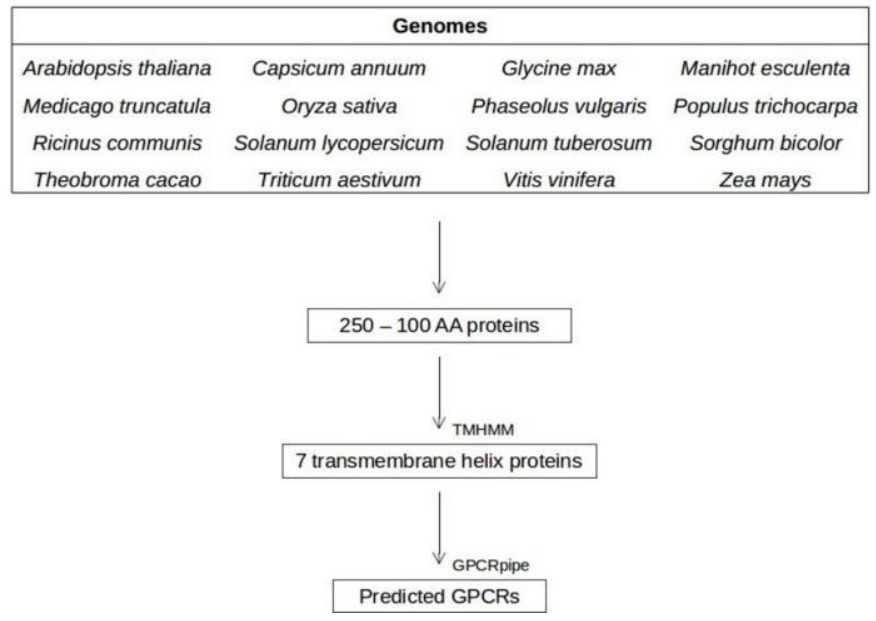

Fig. 1: Data analysis framework for prediction of GPCRs in plant genomes. 
Table 2. Number of proteins and GPCR candidates for each plant species genome selected.

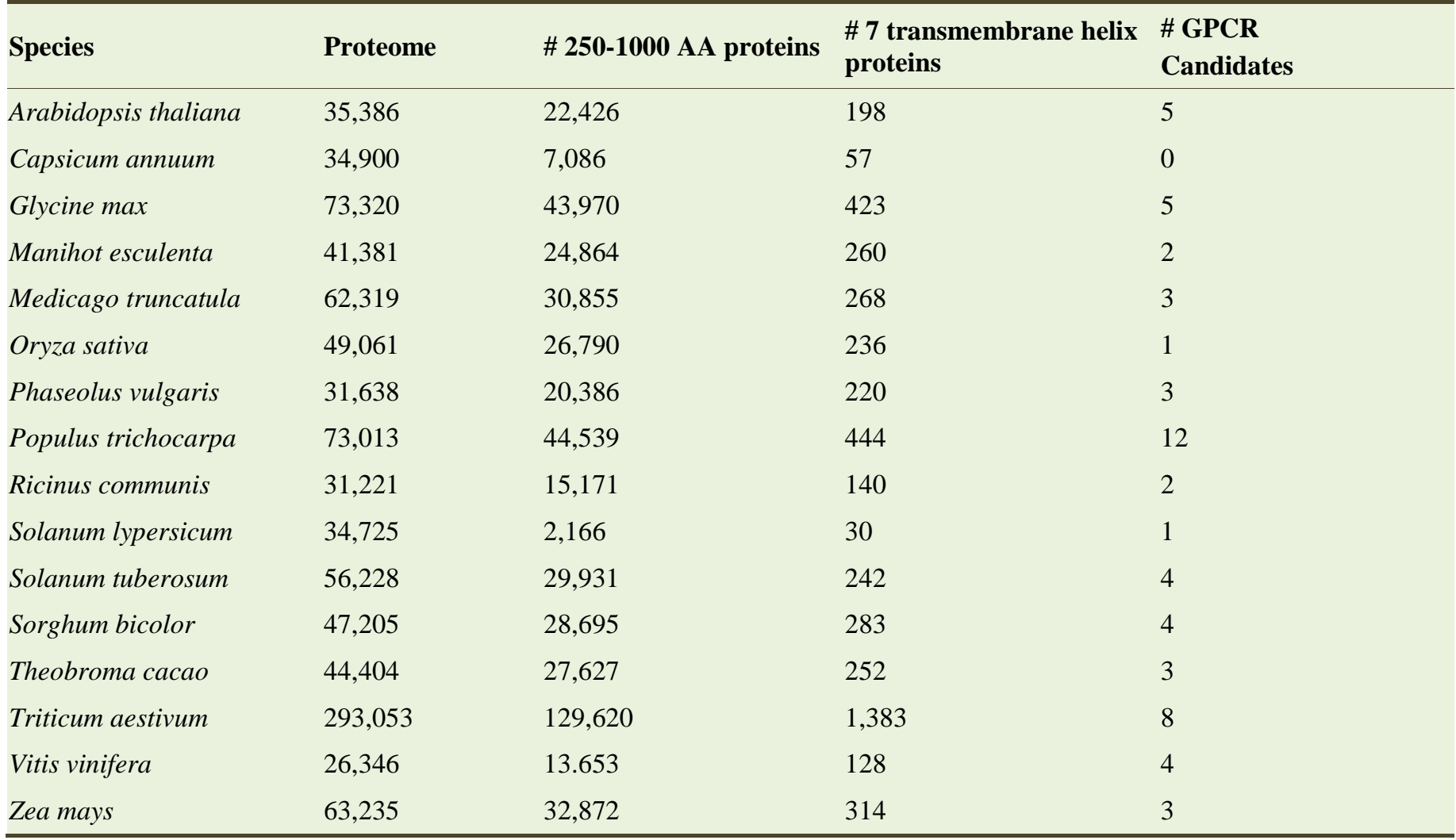

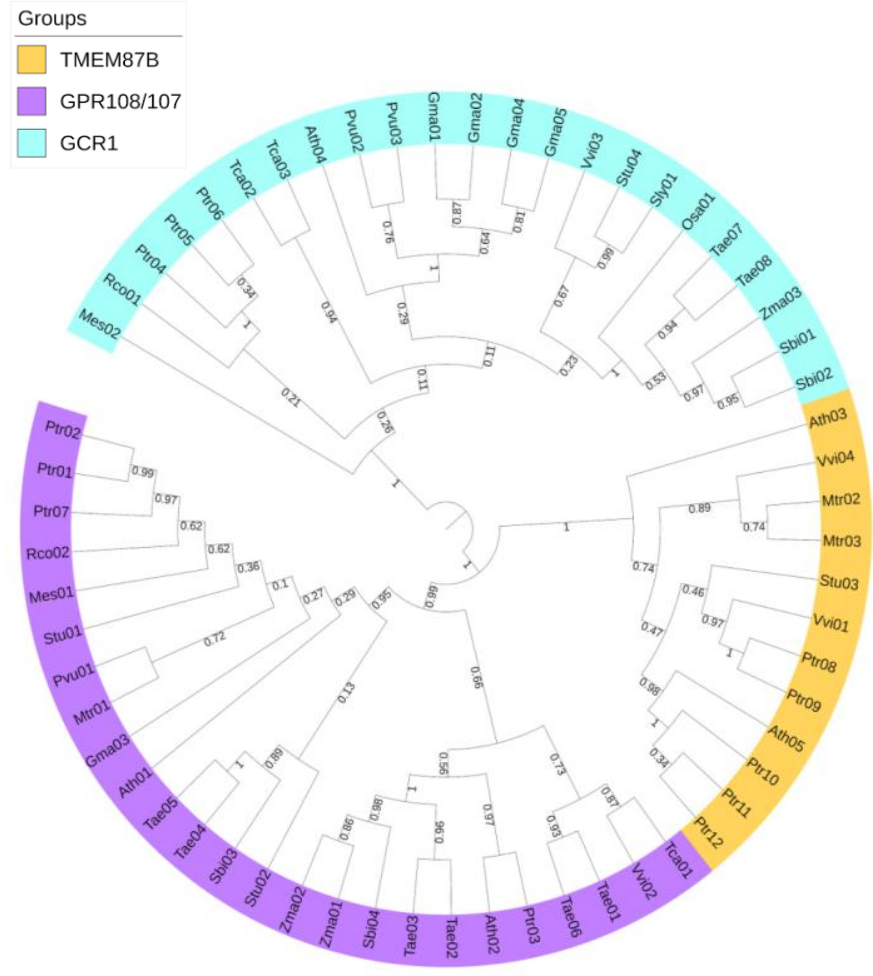

Fig. 2: Neighbor joining dendrogram of the 60 predicted GPCR candidates. Bootstrap values (10,000 replications) are written on the branches. Color-code corresponds to GPCR Classes.
The Neighbor joining dendrogram of the 60 predicted GPCR candidates grouped the proteins in three clades, corresponding to domains $G$ protein-coupled receptor 1 (GCR1), G protein-coupled receptor 108 (GPR108) and Transmembrane protein 87B (TMEM87b) (Figs. 2 and 3). The domains GPR108 and TMEM87b are members of subfamilies A and B, respectively, of the Lung seven transmembrane (LUSTR) family. They are found in plants, animals and in fungi (Edgar, 2007). Sequence comparison of the 60 candidates is shown in Fig. 4.

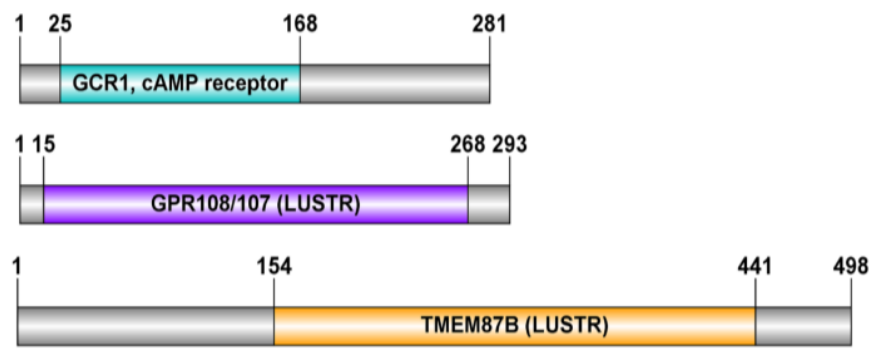

Fig. 3: Structure of conserved domains of putative Plant GPCRs. GCR1, cAMP receptor - G protein-coupled receptor 1 cAMP receptor; GPR108 -G protein-coupled receptor 108 and TMEM87b- Transmembrane protein 87B. The domains GPR108 and TMEM87b are members of subfamilies $A$ and $B$, respectively, of the Lung seven transmembrane (LUSTR) family. 
The clustering in three groups corresponding to the three domains reflect the protein sequence alignment where the GCR1 group show higher conservation in the TM helices segments as well as in the loops, except for the candidate Ptr04 from P. trichocarpa that show an insertion in the sequence. All members of these groups have no signal peptide. The GPR108 group, on the other hand, shows more conservation only on Cterminal and more diversity on the $\mathrm{N}$-terminal segment, corresponding to the extracellular topology. The majority of the sequences present signal peptide. The TMEM 87b group shows high similarity on the core of the protein, corresponding to the topology of transmembrane segments but lack of similarity is observed either on $\mathrm{N}$-terminal as well as in the Cterminal. All members of this groups present signal peptide (Table 3). Table 4 describes the Gene Ontology prediction for each clade, where the group corresponding to GCR1 domain, with 23 protein candidates, is associated with the biological process related to abscisic acid-activated signaling pathway, in the membrane with signal transducer activity. These findings suggest the conservation of GCR1 among plants from different taxonomic families, both monocots and dicots. Among the 60 candidates, 25 are indicated to participate on root morphogenesis and most the 12 candidates like the TMEM87b have no annotation described by Gene Ontology.

\section{(A) GCR1}
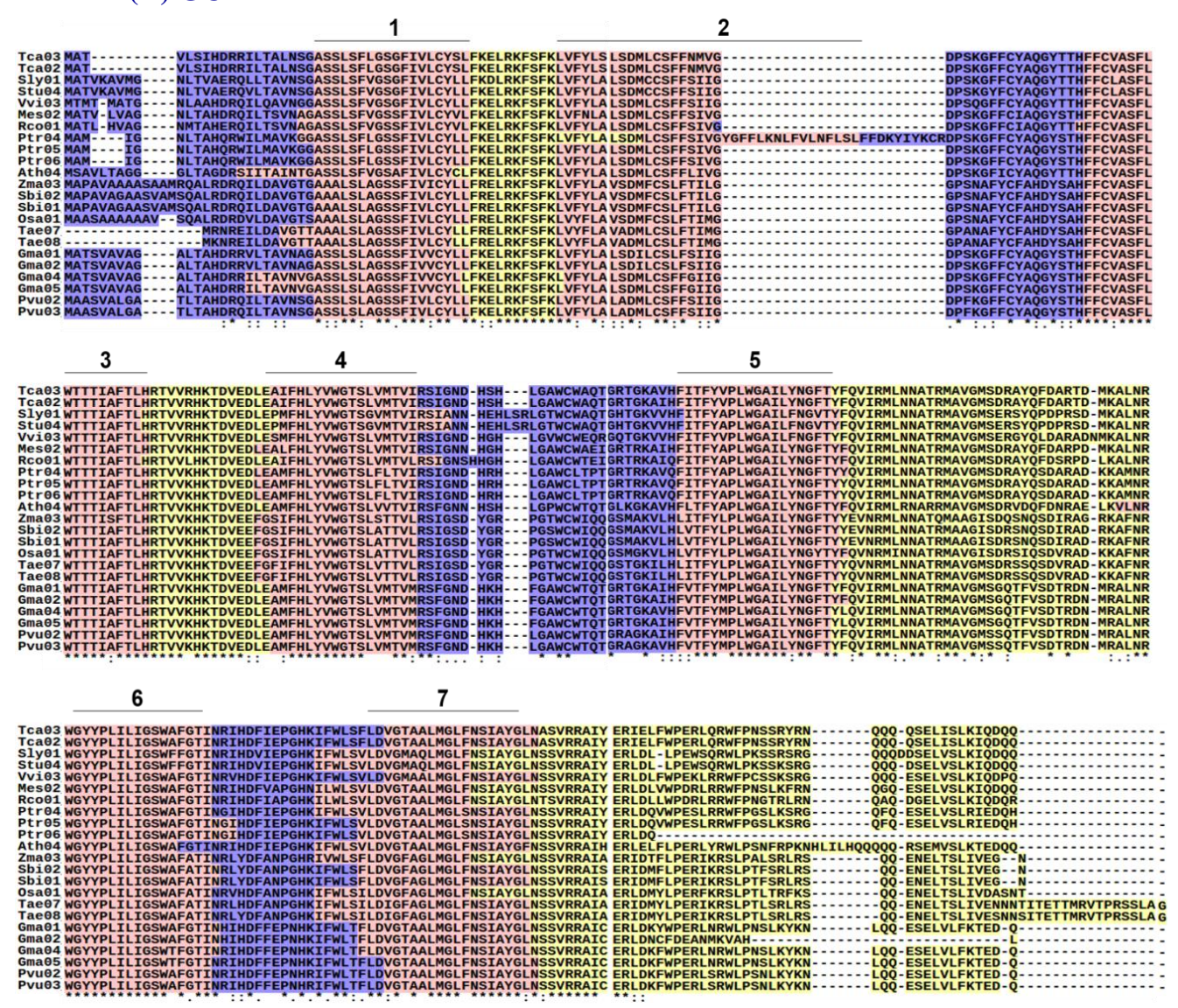

(B) TMEM87b a

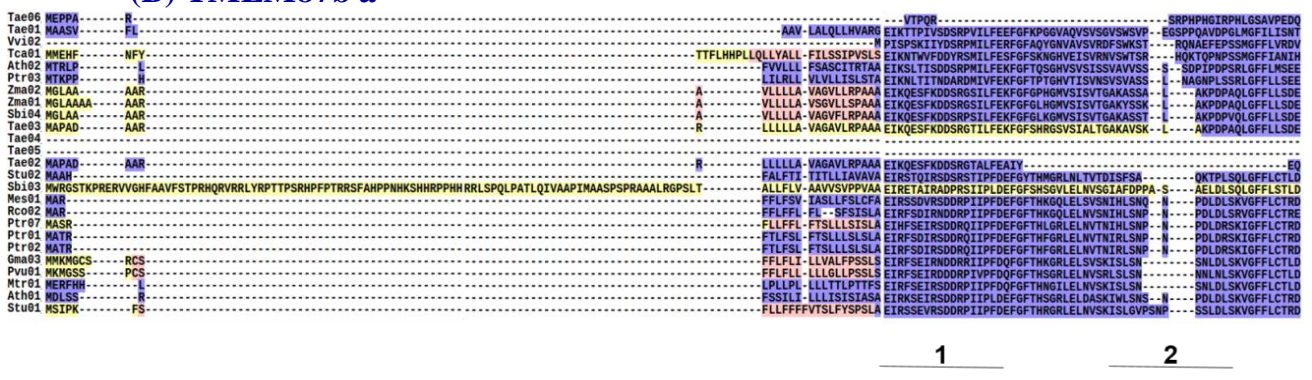




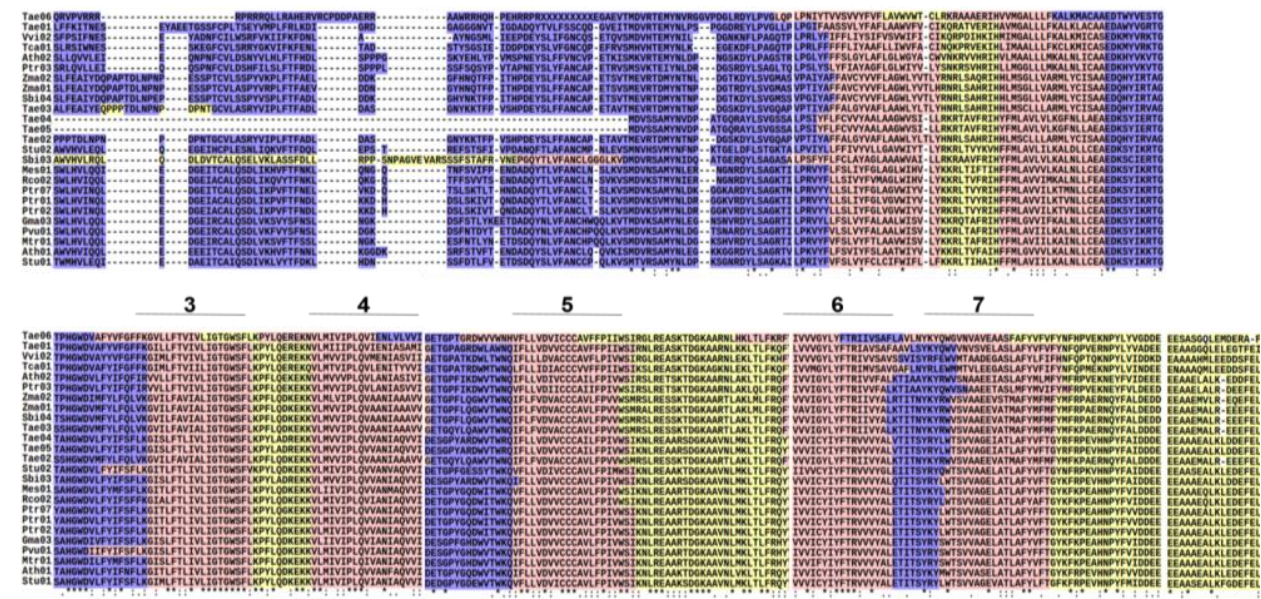

\section{(C) GPR108}

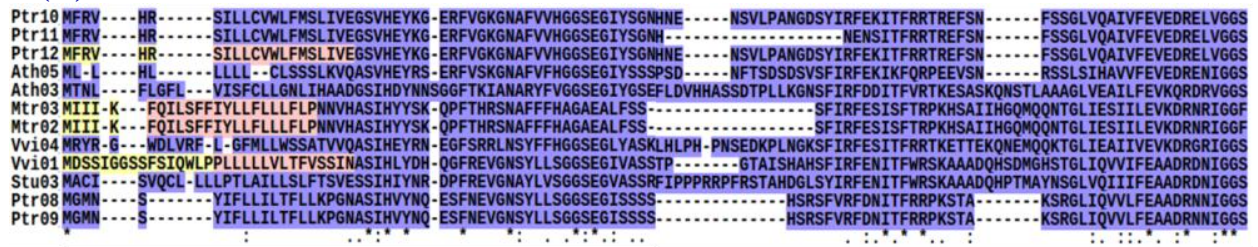

1

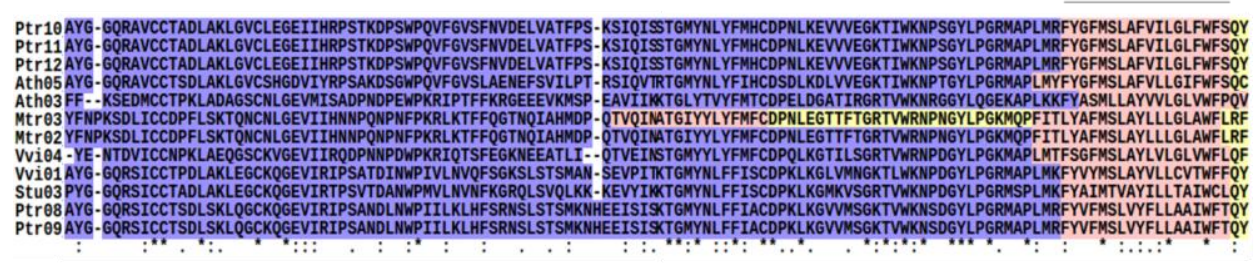

2

4

Ptr10 ARFWREV -....FPLQNCITLVITLGMFEMAFWYFDYAEFNETGIRPTGITLWAVTFGTIKLTVARLVILMVSMGYGVVRPTL-GGLTSKVILVGVTFFVASEVLELVENVGTVSDLSGRARLFLVL

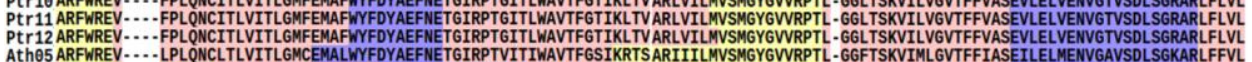

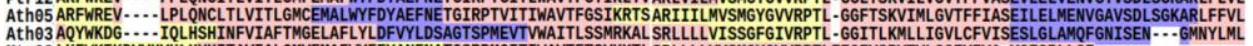

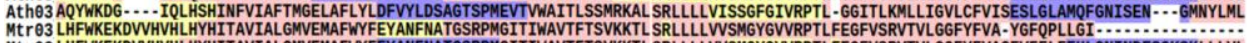

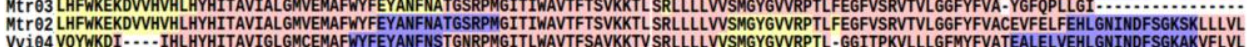
VVi 104 VQYWKDI-..-IHLHYHITAVIGLGMCEMAFWYFEYANFNSTGNRPMGITLWAVTFSAVKKTVSRLLLLVVSMGYGVVPTL-GGITPKVLLLGFMYFVATEALELVEHL GNINDFSGKAKVFLVL

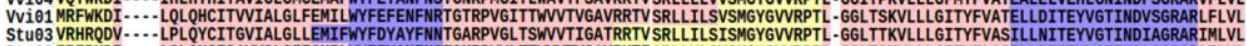

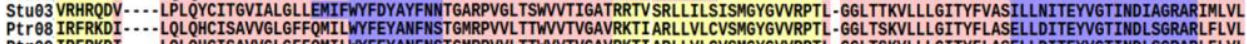

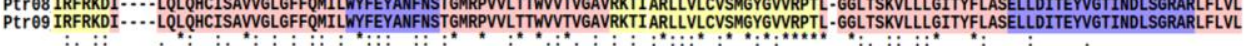

5

Ptr 10 PVSMLDAFIIIWIFKSLSATLNKLQA-KRMMVKLDIYRKFTNALAVAVIVSVGWICYELYFKANDVYNERWONAWVIPAFWRVLSFSLLCVICALWAPSQNSMRYAYSDDASDEFD - .-RDDGTLT Ptr 11 PVSMLDAFIIIWIFKSLSATLNKL QA-KRMMVKLDIYRKFTNALAVAVIVSVGWICYELYFKANDVYNERWQNAWVIPAFWRVLSFSLLCVICALWAPSQNSMRYAYSDDASDEFD $\cdots$. RDDGTLT

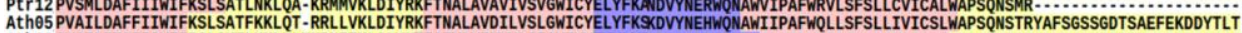
AthO3 SWAILETCFIQWIFRSLSKTLKKLKLNKRNITKLQLYKMFATVLVIMVVLSFAWTYVEVYLYS--SLSOFWKVKWIVPTLWYILSYAMLVLICLFWPPSEKPMRYLYVADMEEETE--EEE-DDLS

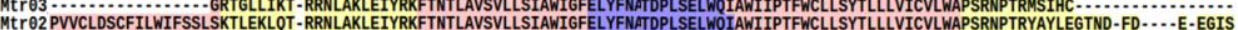

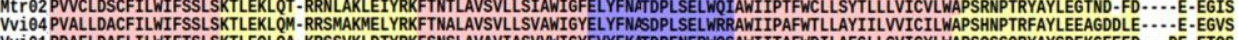
VVI01 PDAFLAAFLIWIFTSLSKTLEQLOA-KRSSVKLDTYRKFSNSLAVAVIASVWWIGYEVYFKATDPFNERWQSAWIITAFWOILAFGLLCVICYLWAPSQSSQRYAYSDERGEEFD...DE-ETQS PT 18 PDALLDAFLILWIFTALSKTLEQLOV-KRSAVKLDIYRKFSNALAAVVFASVAWIAYELYFKATDPFSERWOSAWIITAFWDILAFALLCVICYLWAPSOSSORYAYSEELGEEFD…EE-EAQS PtrO9 PDALLDAFLILWIFTALSKTLEQLQV-KRSAVKLDIYRKFSNALAAVVFASVAWIAYELYFKATDPFSERWQSAWIITAFWDILAFALLCVICYLWAPSQSSQRYAYSEELGEEFD -...EE-EAQS

Ptr10LIKPSTIPSKDVRSALEPRPV.......OASN-GASNSDSEEDKRE Ptr11LIKPSTPSKDVRSALEPRP........AASN-GASNSDSEERKRE

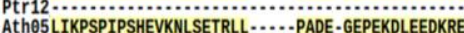
AthO3TAETGM- - NATKAE-YERSERKTL - -LEAFILLLGN-IPGEKMtr 2 2LTSSVAKMTGDVASKLERKERIGS... SATD.LTFGDDIEEDKRE VVIOALTTSGVKVAGDVATKLERKERKVSIAADHV-YGLGEDPEEDKRE Vvi01LTRGKP..EGDISLAKQD ................. NLEDEEEEDKRE Ptr 18 LITREKP...DGDISLVEKKEKS.VG.-GTRV-FDEDGEAEEDKRE PtrO9LTREKP.. DGDISLVEKKEKS.VG.-.GTRV. FDEDGEAEEDKRE

Fig. 4: Multiple sequence alignment for the transmembrane domain regions of the putative Plant GPCRs. Yellow: Intracellular loops, Pink: transmembrane helices, Blue: Extracellular loops. (A) GCR1, (B) TMEM87b a (C) GPR108. 
Table 3. Dataset sources and versions used for GPCR detection.

\begin{tabular}{|c|c|c|c|c|c|c|c|c|c|}
\hline \multicolumn{3}{|c|}{ GPCR candidate } & \multicolumn{2}{|l|}{ Blast Results } & \multirow[b]{2}{*}{ Species } & \multirow{2}{*}{$\begin{array}{l}\text { TMHMM } \\
\text { prediction }\end{array}$} & \multirow{2}{*}{$\begin{array}{l}\text { Signal P } \\
\text { prediction }\end{array}$} & \multirow{2}{*}{ Group } & \multirow{2}{*}{ Class prediction } \\
\hline Id & Seq Name & Species & Accession & Description & & & & & \\
\hline Ath01 & AT5G42090.1 & Arabidopsis thaliana & NM_123574 & $\begin{array}{l}\text { lung seven transmembrane receptor family } \\
\text { protein }\end{array}$ & Arabidopsis thaliana & 7 & Yes & Gr 2 & $\begin{array}{l}\text { Amine Subfamily of } \\
\text { CLASS A }\end{array}$ \\
\hline Ath02 & AT3G09570.1 & Arabidopsis thaliana & NM_111791 & $\begin{array}{l}\text { lung seven transmembrane receptor family } \\
\text { protein }\end{array}$ & Arabidopsis thaliana & 7 & Yes & Gr 2 & $\begin{array}{l}\text { Amine Subfamily of } \\
\text { CLASS A }\end{array}$ \\
\hline Ath03 & AT1G10980.1 & Arabidopsis thaliana & NM_100973 & $\begin{array}{l}\text { Lung seven transmembrane receptor family } \\
\text { protein }\end{array}$ & Arabidopsis thaliana & 7 & Yes & Gr 3 & $\begin{array}{l}\text { Amine Subfamily of } \\
\text { CLASS A }\end{array}$ \\
\hline Ath04 & AT1G48270.1_(GCR1) & Arabidopsis thaliana & NM_103724 & G-protein-coupled receptor 1 & Arabidopsis thaliana & 7 & No & Gr 1 & $\begin{array}{l}\text { Amine Subfamily of } \\
\text { CLASS A }\end{array}$ \\
\hline Ath05 & AT1G72480.1 & Arabidopsis thaliana & NM_105907 & $\begin{array}{l}\text { Lung seven transmembrane receptor family } \\
\text { protein }\end{array}$ & Arabidopsis thaliana & 7 & Yes & Gr 3 & $\begin{array}{l}\text { Amine Subfamily of } \\
\text { CLASS A }\end{array}$ \\
\hline Gma01 & Glyma14g12700.2 & Glycine max & XM_007035944 & G-protein-coupled receptor 1 isoform 1 & Theobroma cacao & 7 & No & Gr 1 & Not a GPCR \\
\hline Gma02 & Glyma14g12700.3 & Glycine max & XM_007035944 & G-protein-coupled receptor 1 isoform 1 & Theobroma cacao & 7 & No & Gr 1 & Not a GPCR \\
\hline Gma03 & Glyma02g09690.1 & Glycine $\max$ & XM_013605659 & $\begin{array}{l}\text { lung seven transmembrane receptor family } \\
\text { protein }\end{array}$ & Medicago truncatula & 7 & Yes & Gr 2 & $\begin{array}{l}\text { Amine Subfamily of } \\
\text { CLASS A }\end{array}$ \\
\hline Gma04 & Glyma17g33480.1 & Glycine max & XM_007035944 & G-protein-coupled receptor 1 isoform 1 & Theobroma cacao & 7 & No & Gr 1 & Not a GPCR \\
\hline Gma05 & Glyma17g33480.2 & Glycine max & XM_007035944 & G-protein-coupled receptor 1 isoform 1 & Theobroma cacao & 7 & No & Gr 1 & Not a GPCR \\
\hline Mes01 & Manes.02G001900.1.p & Manihot esculenta & XM_007039313 & $\begin{array}{l}\text { Lung seven transmembrane receptor family } \\
\text { protein }\end{array}$ & Theobroma cacao & 7 & Yes & Gr 2 & $\begin{array}{l}\text { Amine Subfamily of } \\
\text { CLASS A }\end{array}$ \\
\hline Mes02 & Manes.03G212200.1.p & Manihot esculenta & XM_007035944 & G-protein-coupled receptor 1 isoform 1 & Theobroma cacao & 7 & No & Gr 1 & $\begin{array}{l}\text { Amine Subfamily of } \\
\text { CLASS A }\end{array}$ \\
\hline Mtr01 & Medtr3g080830.1 & Medicago truncatula & XM_013605659 & $\begin{array}{l}\text { lung seven transmembrane receptor family } \\
\text { protein }\end{array}$ & Medicago truncatula & 7 & Yes & Gr 2 & $\begin{array}{l}\text { Amine Subfamily of } \\
\text { CLASS A }\end{array}$ \\
\hline Mtr02 & Medtr8g005790.1 & Medicago truncatula & XM_003626631 & $\begin{array}{l}\text { lung seven transmembrane receptor family } \\
\text { protein }\end{array}$ & Medicago truncatula & 7 & Yes & Gr 3 & $\begin{array}{l}\text { Amine Subfamily of } \\
\text { CLASS A }\end{array}$ \\
\hline Mtr03 & Medtr8g005485.1 & Medicago truncatula & XM_013588310 & $\begin{array}{l}\text { lung seven transmembrane receptor family } \\
\text { protein }\end{array}$ & Medicago truncatula & 7 & Yes & Gr 3 & $\begin{array}{l}\text { Amine Subfamily of } \\
\text { CLASS A }\end{array}$ \\
\hline Osa01 & LOC_Os06g09930.1 & Oryza sativa & NM_001153424 & G protein-coupled receptor & Zea mays & 7 & No & Gr 1 & Not a GPCR \\
\hline Ptr01 & Potri.003G147700.2 & Populus trichocarpa & XM_007039313 & $\begin{array}{l}\text { Lung seven transmembrane receptor family } \\
\text { protein }\end{array}$ & Theobroma cacao & 7 & Yes & Gr 2 & $\begin{array}{l}\text { Amine Subfamily of } \\
\text { CLASS A }\end{array}$ \\
\hline Ptr02 & Potri.003G147700.1 & Populus trichocarpa & XM_007039313 & $\begin{array}{l}\text { Lung seven transmembrane receptor family } \\
\text { protein }\end{array}$ & Theobroma cacao & 7 & Yes & Gr 2 & $\begin{array}{l}\text { Amine Subfamily of } \\
\text { CLASS A }\end{array}$ \\
\hline Ptr03 & Potri.006G214900.1 & Populus trichocarpa & XM_007027081 & $\begin{array}{l}\text { Lung seven transmembrane receptor family } \\
\text { protein }\end{array}$ & Theobroma cacao & 7 & Yes & Gr 2 & $\begin{array}{l}\text { Amine Subfamily of } \\
\text { CLASS A }\end{array}$ \\
\hline Ptr04 & Potri.008G206000.1 & Populus trichocarpa & XM_002311815 & G-protein-COUPLED RECEPTOR 1 & Populus trichocarpa & 7 & No & Gr 1 & $\begin{array}{l}\text { Amine Subfamily of } \\
\text { CLASS A }\end{array}$ \\
\hline Ptr05 & Potri.008G206000.2 & Populus trichocarpa & XM_002311815 & G-protein-COUPLED RECEPTOR 1 & Populus trichocarpa & 7 & No & Gr 1 & $\begin{array}{l}\text { Amine Subfamily of } \\
\text { CLASS A }\end{array}$ \\
\hline Ptr06 & Potri.008G206000.3 & Populus trichocarpa & XM_002311815 & G-protein-COUPLED RECEPTOR 1 & Populus trichocarpa & 7 & No & Gr 1 & Not a GPCR \\
\hline Ptr07 & Potri.001G083100.1 & Populus trichocarpa & XM_007039313 & $\begin{array}{l}\text { Lung seven transmembrane receptor family } \\
\text { protein }\end{array}$ & Theobroma cacao & 7 & Yes & Gr 2 & $\begin{array}{l}\text { Amine Subfamily of } \\
\text { CLASS A }\end{array}$ \\
\hline Ptr08 & Potri.001G209400.2 & Populus trichocarpa & XM_007041491 & $\begin{array}{l}\text { Lung seven transmembrane receptor family } \\
\text { protein }\end{array}$ & Theobroma cacao & 7 & Yes & Gr 3 & $\begin{array}{l}\text { Amine Subfamily of } \\
\text { CLASS A }\end{array}$ \\
\hline
\end{tabular}




\begin{tabular}{|c|c|c|c|c|c|c|c|c|c|}
\hline \multicolumn{3}{|c|}{ GPCR candidate } & \multicolumn{2}{|l|}{ Blast Results } & \multirow[b]{2}{*}{ Species } & \multirow{2}{*}{$\begin{array}{l}\text { TMHMM } \\
\text { prediction }\end{array}$} & \multirow{2}{*}{$\begin{array}{l}\text { Signal P } \\
\text { prediction }\end{array}$} & \multirow{2}{*}{ Group } & \multirow{2}{*}{ Class prediction } \\
\hline Id & Seq Name & Species & Accession & Description & & & & & \\
\hline Ptr09 & Potri.001G209400.1 & Populus trichocarpa & XM_007041491 & $\begin{array}{l}\text { Lung seven transmembrane receptor family } \\
\text { protein }\end{array}$ & Theobroma cacao & 7 & Yes & Gr 3 & $\begin{array}{l}\text { Amine Subfamily of } \\
\text { CLASS A }\end{array}$ \\
\hline Ptr10 & Potri.001G166500.1 & Populus trichocarpa & XM_007024608 & $\begin{array}{l}\text { Lung seven transmembrane receptor family } \\
\text { protein isoform } 1\end{array}$ & Theobroma cacao & 7 & Yes & Gr 3 & $\begin{array}{l}\text { Amine Subfamily of } \\
\text { CLASS A }\end{array}$ \\
\hline Ptr11 & Potri.001G166500.2 & Populus trichocarpa & XM_007024608 & $\begin{array}{l}\text { Lung seven transmembrane receptor family } \\
\text { protein isoform } 1\end{array}$ & Theobroma cacao & 7 & Yes & Gr 3 & $\begin{array}{l}\text { Amine Subfamily of } \\
\text { CLASS A }\end{array}$ \\
\hline Ptr12 & Potri.001G166500.3 & Populus trichocarpa & XM_007024608 & $\begin{array}{l}\text { Lung seven transmembrane receptor family } \\
\text { protein isoform } 1\end{array}$ & Theobroma cacao & 7 & Yes & Gr 3 & $\begin{array}{l}\text { Amine Subfamily of } \\
\text { CLASS A }\end{array}$ \\
\hline Pvu01 & Phvul.004G090500.1 & Phaseolus vulgaris & XM_013605659 & $\begin{array}{l}\text { lung seven transmembrane receptor family } \\
\text { protein }\end{array}$ & Medicago truncatula & 7 & Yes & Gr 2 & $\begin{array}{l}\text { Amine Subfamily of } \\
\text { CLASS A }\end{array}$ \\
\hline Pvu02 & Phvul.001G044800.1 & Phaseolus vulgaris & XM_007035944 & G-protein-coupled receptor 1 isoform 1 & Theobroma cacao & 7 & No & Gr 1 & $\begin{array}{l}\text { Amine Subfamily of } \\
\text { CLASS A }\end{array}$ \\
\hline Pvu03 & Phvul.001G044800.2 & Phaseolus vulgaris & XM_007035944 & G-protein-coupled receptor 1 isoform 1 & Theobroma cacao & 7 & No & Gr 1 & $\begin{array}{l}\text { Amine Subfamily of } \\
\text { CLASS A }\end{array}$ \\
\hline Rco01 & 29889.m003405 & Ricinus communis & XM_007035944 & G-protein-coupled receptor 1 isoform 1 & Theobroma cacao & 7 & No & Gr 1 & $\begin{array}{l}\text { Amine Subfamily of } \\
\text { CLASS A }\end{array}$ \\
\hline Rco02 & 30068.m002586 & Ricinus communis & XM_007039313 & $\begin{array}{l}\text { Lung seven transmembrane receptor family } \\
\text { protein }\end{array}$ & Theobroma cacao & 7 & Yes & Gr 2 & $\begin{array}{l}\text { Amine Subfamily of } \\
\text { CLASS A }\end{array}$ \\
\hline Sbi01 & Sobic.010G074900.1.p & Sorghum bicolor & NM_001153424 & G protein-coupled receptor & Zea mays & 7 & No & Gr 1 & $\begin{array}{l}\text { Amine Subfamily of } \\
\text { CLASS A }\end{array}$ \\
\hline Sbi02 & Sobic.010G074900.2.p & Sorghum bicolor & NM_001153424 & G protein-coupled receptor & Zea mays & 7 & No & Gr 1 & $\begin{array}{l}\text { Amine Subfamily of } \\
\text { CLASS A }\end{array}$ \\
\hline Sbi03 & Sobic.010G022300.2.p & Sorghum bicolor & XM_007039313 & $\begin{array}{l}\text { Lung seven transmembrane receptor family } \\
\text { protein }\end{array}$ & Theobroma cacao & 7 & No & Gr 2 & $\begin{array}{l}\text { Amine Subfamily of } \\
\text { CLASS A }\end{array}$ \\
\hline Sbi04 & Sobic.003G348200.1.p & Sorghum bicolor & NM_121857 & candidate G-protein Coupled Receptor 7 & Arabidopsis thaliana & 7 & Yes & Gr 2 & $\begin{array}{l}\text { Amine Subfamily of } \\
\text { CLASS A }\end{array}$ \\
\hline Sly01 & Solyc08g061260.2.1 & Solanum lycopersicum & XM_007035944 & G-protein-coupled receptor 1 isoform 1 & Theobroma cacao & 7 & No & Gr 1 & $\begin{array}{l}\text { Amine Subfamily of } \\
\text { CLASS A }\end{array}$ \\
\hline Stu01 & PGSC0003DMP400010386 & Solanum tuberosum & XM_007039313 & $\begin{array}{l}\text { Lung seven transmembrane receptor family } \\
\text { protein }\end{array}$ & Theobroma cacao & 7 & Yes & Gr 2 & $\begin{array}{l}\text { Amine Subfamily of } \\
\text { CLASS A }\end{array}$ \\
\hline Stu02 & PGSC0003DMP400052623 & Solanum tuberosum & XM_007039313 & $\begin{array}{l}\text { Lung seven transmembrane receptor family } \\
\text { protein }\end{array}$ & Theobroma cacao & 7 & Yes & Gr 2 & $\begin{array}{l}\text { Amine Subfamily of } \\
\text { CLASS A }\end{array}$ \\
\hline Stu03 & PGSC0003DMP400031132 & Solanum tuberosum & XM_007041491 & $\begin{array}{l}\text { Lung seven transmembrane receptor family } \\
\text { protein }\end{array}$ & Theobroma cacao & 7 & Yes & Gr 3 & $\begin{array}{l}\text { Amine Subfamily of } \\
\text { CLASS A }\end{array}$ \\
\hline Stu04 & PGSC0003DMP400023027 & Solanum tuberosum & XM_007035944 & G-protein-coupled receptor 1 isoform 1 & Theobroma cacao & 7 & No & GR 1 & $\begin{array}{l}\text { Amine Subfamily of } \\
\text { CLASS A }\end{array}$ \\
\hline Tae01 & Traes_2BL_E9C46CB57.1 & Triticum aestivum & NM_001158876 & protein GPR106 & Zea mays & 7 & Yes & Gr 2 & $\begin{array}{l}\text { Amine Subfamily of } \\
\text { CLASS A }\end{array}$ \\
\hline Tae02 & Traes_3B_E2D1FD54F.1 & Triticum aestivum & NM_111791 & $\begin{array}{l}\text { lung seven transmembrane receptor family } \\
\text { protein }\end{array}$ & Arabidopsis thaliana & 7 & Yes & Gr 2 & $\begin{array}{l}\text { Amine Subfamily of } \\
\text { CLASS A }\end{array}$ \\
\hline Tae03 & Traes_3B_E2D1FD54F.2 & Triticum aestivum & NM_111791 & $\begin{array}{l}\text { lung seven transmembrane receptor family } \\
\text { protein }\end{array}$ & Arabidopsis thaliana & 7 & Yes & Gr 2 & $\begin{array}{l}\text { Amine Subfamily of } \\
\text { CLASS A }\end{array}$ \\
\hline Tae04 & Traes_4AL_F4A73435D.1 & Triticum aestivum & NM_123574 & $\begin{array}{l}\text { lung seven transmembrane receptor family } \\
\text { protein }\end{array}$ & Arabidopsis thaliana & 7 & No & Gr 2 & $\begin{array}{l}\text { Amine Subfamily of } \\
\text { CLASS A }\end{array}$ \\
\hline Tae05 & Traes_4AL_F4A73435D.2 & Triticum aestivum & NM_123574 & $\begin{array}{l}\text { lung seven transmembrane receptor family } \\
\text { protein }\end{array}$ & Arabidopsis thaliana & 7 & No & Gr 2 & $\begin{array}{l}\text { Amine Subfamily of } \\
\text { CLASS A }\end{array}$ \\
\hline Tae06 & Traes_6AL_3320984F2.1 & Triticum aestivum & NM_001158273 & protein GPR107 & Zea mays & 7 & No & Gr 2 & $\begin{array}{l}\text { Amine Subfamily of } \\
\text { CLASS A }\end{array}$ \\
\hline
\end{tabular}




\begin{tabular}{|c|c|c|c|c|c|c|c|c|c|}
\hline \multicolumn{3}{|c|}{ GPCR candidate } & \multicolumn{2}{|l|}{ Blast Results } & \multirow[b]{2}{*}{ Species } & \multirow{2}{*}{$\begin{array}{l}\text { TMHMM } \\
\text { prediction }\end{array}$} & \multirow{2}{*}{$\begin{array}{l}\text { Signal P } \\
\text { prediction }\end{array}$} & \multirow{2}{*}{ Group } & \multirow{2}{*}{ Class prediction } \\
\hline Id & Seq Name & Species & Accession & Description & & & & & \\
\hline Tae07 & Traes_7AS_57E069383.1 & Triticum aestivum & NM_001153424 & G protein-coupled receptor & Zea mays & 7 & No & Gr 1 & $\begin{array}{l}\text { Amine Subfamily of } \\
\text { CLASS A }\end{array}$ \\
\hline Tae08 & Traes_7DS_653DD38AF.1 & Triticum aestivum & NM_001153424 & G protein-coupled receptor & Zea mays & 7 & No & Gr 1 & $\begin{array}{l}\text { Amine Subfamily of } \\
\text { CLASS A }\end{array}$ \\
\hline Tca01 & Thecc1EG026130t1 & Theobroma cacao & NM_001158876 & Lung seven transmembrane receptor, putative & Theobroma cacao & 7 & Yes & Gr 2 & $\begin{array}{l}\text { Amine Subfamily of } \\
\text { CLASS A }\end{array}$ \\
\hline Tca02 & Thecc1EG021504t1 & Theobroma cacao & XM_007035944 & G-protein-coupled receptor 1 isoform 1 & Theobroma cacao & 7 & No & Gr 1 & $\begin{array}{l}\text { Amine Subfamily of } \\
\text { CLASS A }\end{array}$ \\
\hline Tca03 & Thecc1EG021504t2 & Theobroma cacao & XM_007035945 & G-protein-coupled receptor 1 isoform 1 & Theobroma cacao & 7 & No & Gr 1 & $\begin{array}{l}\text { Amine Subfamily of } \\
\text { CLASS A }\end{array}$ \\
\hline Vvi01 & GSVIVT01023009001 & Vitis vinifera & XM_007041491 & $\begin{array}{l}\text { Lung seven transmembrane receptor family } \\
\text { protein }\end{array}$ & Theobroma cacao & 7 & Yes & Gr 3 & $\begin{array}{l}\text { Amine Subfamily of } \\
\text { CLASS A }\end{array}$ \\
\hline Vvi02 & GSVIVT01026321001 & Vitis vinifera & NM_001158876 & Lung seven transmembrane receptor, putative & Theobroma cacao & 7 & No & Gr 2 & $\begin{array}{l}\text { Amine Subfamily of } \\
\text { CLASS A }\end{array}$ \\
\hline Vvi03 & GSVIVT01035487001 & Vitis vinifera & XM_007035945 & G-protein-coupled receptor 1 isoform 1 & Theobroma cacao & 7 & No & Gr 1 & $\begin{array}{l}\text { Amine Subfamily of } \\
\text { CLASS A }\end{array}$ \\
\hline Vvi04 & GSVIVT01032664001 & Vitis vinifera & XM_003615364 & $\begin{array}{l}\text { lung seven transmembrane receptor family } \\
\text { protein }\end{array}$ & Medicago truncatula & 7 & Yes & Gr 3 & $\begin{array}{l}\text { Amine Subfamily of } \\
\text { CLASS A }\end{array}$ \\
\hline Zma01 & AC214448.3_FGP007 & Zea mays & NM_001157220 & transmembrane receptor & Zea mays & 7 & Yes & Gr 2 & $\begin{array}{l}\text { Amine Subfamily of } \\
\text { CLASS A }\end{array}$ \\
\hline Zma02 & GRMZM2G179985_P01 & Zea mays & NM_121857 & candidate G-protein Coupled Receptor 8 & Arabidopsis thaliana & 7 & Yes & Gr 2 & $\begin{array}{l}\text { Amine Subfamily of } \\
\text { CLASS A }\end{array}$ \\
\hline Zma03 & GRMZM2G120371_P01 & Zea mays & NM_001153424 & G protein-coupled receptor & Zea mays & 7 & No & Gr 1 & Not a GPCR \\
\hline
\end{tabular}

Table 4. Gene ontology analysis ofthe GPCR candidates.

\begin{tabular}{|c|c|c|c|}
\hline Domains & Biological process annotation & Cellular component annotation & Molecular function annotation \\
\hline GCR 1 & $\begin{array}{l}\text { Abscisic acid-activated signaling pathway } \\
\text { Activation of phospholipase C activity } \\
\text { Cell cycle } \\
\text { G-protein coupled receptor signaling pathway } \\
\text { Lipid metabolic process } \\
\text { Maintenance of seed dormancy } \\
\text { Mitotic cell cycle } \\
\text { Regulation of inositol trisphosphate biosynthetic process } \\
\text { Response to low fluence blue light stimulus } \\
\text { Tyrosine biosynthetic process }\end{array}$ & $\begin{array}{l}\text { Golgi apparatus } \\
\text { Integral component of membrane } \\
\text { Membrane } \\
\text { Plasma membrane } \\
\text { Spanning component of plasma membrane } \\
\text { Vacuolar membrane }\end{array}$ & $\begin{array}{l}\text { G-protein coupled receptor activity } \\
\text { protein binding } \\
\text { Signal transducer activity } \\
\text { Transmembrane signaling receptor activity }\end{array}$ \\
\hline GPR107/108 (LUSTR) & $\begin{array}{l}\text { Response to molecule of bacterial origin } \\
\text { Root morphogenesis }\end{array}$ & $\begin{array}{l}\text { Integral component of membrane } \\
\text { Membrane } \\
\text { Trans-Golgi network }\end{array}$ & No annotation \\
\hline TMEM87B (LUSTR) & No annotation & No annotation & No annotation \\
\hline
\end{tabular}




\section{Discussion}

Genomic sequencing has provided a vast resource for identifying interesting genes, but the discovery of new GPCR in plant genomes is not straightforward. The proteins often show low sequence similarities and there is a huge lack of experimental information about plant GPCRs structure-function relationship (Taddese et al., 2014). The usual protein sequence search is not able to detect new GPCRs candidates, although sharing similar structural topology (Zhang, 2012) as GPCRs vary dramatically in development of logic survey and prediction of candidates through bioinformatics studies, before their experimental validation during the past two decades (Yarnitzky et al., 2010). This matter remains under constant review and development (Esguerra et al., 2016; Lu and Wu, 2016; Zhang, 2012).

According to Urano and Jones (2014), plant G proteins spontaneously release GDP and bind GTP in vitro, and thus are self-activating and in contrast to animal mechanisms, the presence of a signal inhibits deactivation of constitutive $G$ activation. The authors conclude that plants do not need classic GPCRs although there are approximately 50 proteins in Arabidopsis and rice that potentially have the same topology as human GPCRs. The lack of experimental elucidation increased the controversy (Coopman et al., 2011; Taddese et al., 2014).

Josefsson and Rask (1997)and Plakidou-Dymock et al. (1998) firstly reported the discovery of a putative classic GPCR in Arabidopsis which concluded that GCR1 encodes the first 7TM receptor homologue identified and was involved in cytokinin signal transduction (Assmann, 2002). Increasing the knowledge on this field, in the last decade, the physiological effect of GCR1 has been investigated and several studies put together information about the seed germination, the interaction with cell signaling mediators, add to the response to brassinosteroids and gibberellins, as well as reducing drought stress (Chakraborty et al., 2015b; Moriyama et al., 2006). Central to this analysis is the prediction of conserved, hydrophobic, seven transmembrane (7-TM) domain that locates the GPCR and dictates its minimum amino acid sequence length ( 260 amino acids) (Davies et al., 2007), despite the low sequence similarity is observed when comparing sequences, usually around $25 \%$.

Thus, to predict GPCRs, the search for topology patterns and the identification of seven hydrophobic regions is one important step (Urano and Jones, 2013). It is, therefore, necessary to consider fold and motifs (Krishnan et al., 2012) to distinguish between GPCRs and other proteins that may share a 7TM scaffold. The observation of conserved domains in GPCR candidates enables an integrated classification and clustering based on secondary structure (Gookin et al., 2008). Our analysis identified signatures involving the role of conserved residues such as the GCR1 domain and the GPR108 and TMEM87b from the Lung seven transmembrane (LUSTR) domain family in the three grouped candidates (Fig. 3 and 4). The LUSTR family has similar predicted topology and weak homology to bovine rhodopsin, a model GPCR. A gene duplication in an ancestral eukaryote has led to the evolution of two subfamilies (LUSTR-A and LUSTR-B) that have diverged significantly, whilst retaining close homology in the LUSTR domain within each subfamily (Edgar, 2007). In each LUSTR subfamily, the third intracellular loop is highly conserved, but distinct from each other. Generally, in other GPCRs, this third intracellular loop is involved in G-protein binding and receptor signaling suggesting that this region of the LUSTR proteins is also involved in G-protein- coupling. Studies in plants support the LUSTR involvement in an abiotic stress response. Cold stressed rice plants differentially express 123 transcripts, including a LUSTR homolog in the leaf tissue (Kim et al., 2007). The function associated to these proteins is still unknown, but high degree of sequence conservation suggests that these genes have retained an important function over long periods of eukaryotic evolution.

Moreover, Cvicek et al. (2016) recently described a list of conserved contact residues and important activation residues that are critical for GPCR folding and function. The authors showed that variants of amino acids at these locations in the GPCRs can alter the activation state and consequently change the cell signaling process. The conserved contacts appear to be conserved inside a class of GPCR structural fold. Furthermore, the authors propose that some residues identify structurally and functionally plant GPCRs candidates (Cvicek et al., 2016; Gookin et al., 2008).

Colaneri and Jones (2014) showed recently that plant Gproteins reach steady state at different active/inactive ratios under certain stresses (e.g. salt stress) the level of active $G \alpha$ subunit and $G \beta \gamma$ is controlled by the energy state of the cell, which is sensed by the glucose level, and transduced by AtRGS1. Therefore, we speculate that new GPCR candidates are mainly related to GCR1 from 
the classical point of view, nevertheless the presence of others receptors and allow an integrative response to stimuli.

\section{GPCRs and drought stress and signaling}

Once perceived by a GPCR the external signal is transmitted into the cytoplasm by interaction with various downstream effectors proteins, providing a ubiquitous signaling mechanism in eukaryotes (Trusov and Botella, 2016). The phytohormone abscisic acid (ABA) plays a central role in plant development and in plant adaptation to both biotic and abiotic stressors. In the past years, much progress has been made on the identification of $\mathrm{ABA}$ receptors and the understanding of the molecular and biochemical mechanisms regarding ABA perception and transduction (Guo et al., 2011). Some studies have identified the GPCR-machinery as ABA receptors, located in various subcellular locations (Liu et al., 2007; Ma et al., 2009; Pandey et al., 2009; Park et al., 2009; Shen et al., 2006).

Under osmotic stress, ABA promotes plant water conservation by decreasing the apertures of stomatal pores in the epidermis. The role of GCR1 in Arabidopsis was investigated by a whole transcriptome microarray analysis of the GCR1-knock-out mutant and revealed that it has an extensive genome wide response. Since GCR1 and G-Protein A1 (GPA1) are physically coupled, it seems that GCR1 may act as a negative regulator of GPA1-mediated ABA responses in guard cells (Chen et al., 2006; Pandey and Assmann, 2004; Yadav et al., 2012). The roles of G-proteins signaling components in Arabidopsis abiotic stress response was validated recently where its functions were related to biotic and abiotic stress, hormone response and secondary metabolism; and consequently, the involvement of GCR1 as a key participant in those processes either independent of, or hitherto unattributed to G-protein was corroborated (Chakraborty et al., 2015b). This suggests that G-protein signaling pathway could offer novel common targets for the development of tolerance/resistance to multiple abiotic stresses allowing further genetic manipulation.

Overall, our findings complement previous studies in papers by Chakraborty et al. (2015b), Fredriksson and Schio (2005), Moriyama et al.(2006) and Taddese et al. (2014)and contribute to end the controversy of GPCRs in plant genomes. We expect that the increase of knowledge in plant genome allow the application and experimental validation of those candidates to contribute to the development of drought stress tolerance crops.

\section{Conclusion}

The strategy we described here overcomes the controversy about plant GPCR presence and strongly suggests the functionality of GPCR candidates in several taxonomic orders of plants. Moreover, the bioinformatic pipeline used in this work logically selected protein set for further experimental validation of their functions. Further studies would show the veritable structurefunction relationship for a complex protein such as GPCRs could be determined by a multidisciplinary approach using both biochemical, structural determination and physiological approach or even genome editing.

\section{Conflict of interest statement}

Authors declare that they have no conflict of interest.

\section{Acknowledgement}

Work in Bioinformatics Lab at Embrapa Genetic Resources and Biotechnology is supported by Grants numbers: CNPq Grant \# 454064/2014-4, CAPES Grant \# $51 / 2013$.

\section{References}

Assmann, S.M., 2002. Heterotrimeric and unconventional GTP binding proteins in plant cell signaling. Plant Cell 14, 355. doi:10.1105/tpc.001792.S356

Bhasin, M., Raghava, G.P.S., 2004. GPCRpred: an SVMbased method for prediction of families and subfamilies of G-protein coupled receptors. Nucleic Acids Res. 32, W383-W389. doi:10.1093/nar/gkh416

Chakraborty, N., Sharma, P., Kanyuka, K., Pathak, R.R., Choudhury, D., Hooley, R.A., Raghuram, N., 2015a. Transcriptome analysis of arabidopsis GCR1 mutant reveals its roles in stress, hormones, secondary metabolism and phosphate starvation. PLoS One 10, 1-17. doi:10.1371/journal.pone.0117819

Chakraborty, N., Singh, N., Kaur, K., Raghuram, N., $2015 b$. G-protein Signaling Components GCR1 and GPA1 Mediate Responses to Multiple Abiotic Stresses in Arabidopsis. Front. Plant Sci. 6, 1000. doi:10.3389/fpls.2015.01000

Chang, J.M., Di Tommaso, P., Taly, J.F., Notredame, C., 2012. Accurate multiple sequence alignment of transmembrane proteins with PSI-Coffee. BMC Bioinformatics 13, S1. doi:10.1186/1471-2105-13-S4-S1

Chen, J., Ellis, B.E., 2008. GCR2 is a new member of the eukaryotic lanthionine synthetase component C-like protein family. Plant Signal. Behav. 3, 307-310. doi: $10.4161 /$ psb.3.5.5292 
Chen, Y., Ji, F., Xie, H., Liang, J., 2006. Overexpression of the regulator of G-protein signalling protein enhances ABAmediated inhibition of root elongation and drought tolerance in Arabidopsis. J. Exp. Bot. 57, 2101-2110. doi:10.1093/jxb/erj167

Colaneri, A.C., Jones, A.M., 2014. The wiring diagram for plant G signaling. Curr. Opin. Plant Biol. 22, 56-64. doi:10.1016/j.pbi.2014.09.004

Coopman, K., Wallis, R., Robb, G., Brown, A.J.H., Wilkinson, G.F., Timms, D., Willars, G.B., 2011. Residues within the Transmembrane Domain of the Glucagon-Like Peptide-1 Receptor Involved in Ligand Binding and Receptor Activation: Modelling the Ligand-Bound Receptor. Mol. Endocrinol. 25, 1804-1818. doi:10.1210/me.2011-1160

Corpet, F., Servant, F., Gouzy, J., Kahn, D., 2000. ProDom and ProDom-CG: tools for protein domain analysis and whole genome comparisons. Nucleic Acids Res. 28, 267269.

Cvicek, V., Goddard, W.A., Abrol, R., 2016. Structure-Based Sequence Alignment of the Transmembrane Domains of All Human GPCRs: Phylogenetic, Structural and Functional Implications, PLoS Computational Biology. doi:10.1371/journal.pcbi.1004805

Davies, M.N., Secker, A., Freitas, A.A., Mendao, M., Timmis, J., Flower, D.R., 2007. On the hierarchical classification of $\mathrm{G}$ protein-coupled receptors. Bioinformatics 23, 31133118. doi:10.1093/bioinformatics/btm506

Edgar, A., 2007. Human GPR107 and murine Gpr108 are members of the LUSTR family of proteins found in both plants and animals, having similar topology to G-protein coupled receptors. DNA Seq. 18, 235-241. doi:10.1080/10425170701207182

Esguerra, M., Siretskiy, A., Bello, X., Sallander, J., Gutiérrezde-Terán, H., 2016. GPCR-ModSim: A comprehensive web based solution for modeling G-protein coupled receptors. Nucleic Acids Res. gkw403. doi:10.1093/nar/gkw403

Fredriksson, R., Schio, H.B., 2005. The Repertoire of GProtein - Coupled Receptors in Fully. Mol. Pharmacol. 67, 1414-1425. doi:10.1124/mol.104.009001.sequenced

Gookin, T.E., Kim, J., Assmann, S.M., 2008. Whole proteome identification of plant candidate G-protein coupled receptors in Arabidopsis, rice, and poplar: computational prediction and in-vivo protein coupling 9. doi:10.1186/gb2008-9-7-r120

Guo, J., Yang, X., Weston, D.J., Chen, J.-G., 2011. Abscisic Acid receptors: past, present and future(f). J. Integr. Plant Biol. 53, 469-79. doi:10.1111/j.1744-7909.2011.01044.x

Higgins, D.G., Sharp, P.M., 1998. CLUSTAL: a package for performing multiple sequence alignment on a microcomputer. Gene 73, 237-244.

Jaillon, O., Aury, J.-M., Noel, B., Policriti, A., Clepet, C., Casagrande, A., Choisne, N., Aubourg, S., Vitulo, N., Jubin, C., Vezzi, A., Legeai, F., Hugueney, P., Dasilva, C., Horner, D., Mica, E., Jublot, D., Poulain, J., Bruyère, C., Billault, A., Segurens, B., Gouyvenoux, M., Ugarte, E., Cattonaro, F., Anthouard, V., Vico, V., Del Fabbro, C.,
Alaux, M., Di Gaspero, G., Dumas, V., Felice, N., Paillard, S., Juman, I., Moroldo, M., Scalabrin, S., Canaguier, A., Le Clainche, I., Malacrida, G., Durand, E., Pesole, G., Laucou, V., Chatelet, P., Merdinoglu, D., Delledonne, M., Pezzotti, M., Lecharny, A., Scarpelli, C., Artiguenave, F., Pè, M.E., Valle, G., Morgante, M., Caboche, M., Adam-Blondon, A.-F., Weissenbach, J., Quétier, F., Wincker, P., 2007. The grapevine genome sequence suggests ancestral hexaploidization in major angiosperm phyla. Nature 449, 463-467. doi:10.1038/nature06148

Jones, P., Binns, D., Chang, H.-Y., Fraser, M., Li, W., McAnulla, C., McWilliam, H., Maslen, J., Mitchell, A., Nuka, G., Pesseat, S., Quinn, A.F., Sangrador-Vegas, A., Scheremetjew, M., Yong, S.-Y., Lopez, R., Hunter, S., 2014. InterProScan 5: genome-scale protein function classification. Bioinformatics 30, 1236-1240. doi:10.1093/bioinformatics/btu031

Josefsson, L.G., Rask, L., 1997. Cloning of a putative Gprotein-coupled receptor from Arabidopsis thaliana. Eur. J. Biochem. 249, 415-20.

Käll, L., Krogh, A., Sonnhammer, E.L.L., 2007. Advantages of combined transmembrane topology and signal peptide prediction-the Phobius web server. Nucleic Acids Res. 35. doi:10.1093/nar/gkm256

Kim, S.H., Kim, J.Y., Kim, S.J., An, K.S., An, G., Kim, S.R., 2007. Isolation of cold stress-responsive genes in the reproductive organs, and characterization of the OsLti6b gene from rice (Oryza sativa L.). Plant Cell Rep. 26, 1097-1110. doi:10.1007/s00299-006-0297-0

Krishnan, A., Almén, M.S., Fredriksson, R., Schiöth, H.B., 2012. The Origin of GPCRs: Identification of Mammalian like Rhodopsin, Adhesion, Glutamate and Frizzled GPCRs in Fungi. PLoS One 7, e29817. doi:10.1371 /journal.pone.0029817

Krogh, A., Larsson, B., von Heijne, G., Sonnhammer, E.L., 2001. Predicting transmembrane protein topology with a hidden Markov model: application to complete genomes. J. Mol. Biol. 305, 567-580. doi:10.1006/jmbi.2000.4315

Lamesch, P., Berardini, T.Z., Li, D., Swarbreck, D., Wilks, C., Sasidharan, R., Muller, R., Dreher, K., Alexander, D.L., Garcia-Hernandez, M., Karthikeyan, A.S., Lee, C.H., Nelson, W.D., Ploetz, L., Singh, S., Wensel, A., Huala, E., 2012. The Arabidopsis Information Resource (TAIR): improved gene annotation and new tools. Nucleic Acids Res. 40, D1202-D1210. doi:10.1093/nar/gkr1090.

Liu, X., Yue, Y., Li, W., Ma, L., 2007. Response to Comment on "A G Protein Coupled Receptor Is a Plasma Membrane Receptor for the Plant Hormone Abscisic Acid." Science (80-. ). 318, 914d-914d. doi:10.1126/science.1143320

Lu, M., Wu, B., 2016. Structural studies of G protein-coupled receptors. IUBMB Life 1-10. doi:10.1002/iub.1578

Ma, Y., Szostkiewicz, I., Korte, A., Moes, D., Yang, Y., Christmann, A., Grill, E., 2009. Regulators of PP2C Phosphatase Activity Function as Abscisic Acid Sensors. Science (80-. ). doi:10.1126/science.1172408

Mayer, K.F.X., Rogers, J., Dole el, J., Pozniak, C., Eversole, 
K., Feuillet, C., Gill, B., Friebe, B., Lukaszewski, A.J., Sourdille, P., Endo, T.R., Kubalakova, M., Ihalikova, J., Dubska, Z., Vrana, J., Perkova, R., Imkova, H., Febrer, M., Clissold, L., McLay, K., Singh, K., Chhuneja, P., Singh, N.K., Khurana, J., Akhunov, E., Choulet, F., Alberti, A., Barbe, V., Wincker, P., Kanamori, H., Kobayashi, F., Itoh, T., Matsumoto, T., Sakai, H., Tanaka, T., Wu, J., Ogihara, Y., Handa, H., Maclachlan, P.R., Sharpe, A., Klassen, D., Edwards, D., Batley, J., Olsen, O.-A., Sandve, S.R., Lien, S., Steuernagel, B., Wulff, B., Caccamo, M., Ayling, S., Ramirez-Gonzalez, R.H., Clavijo, B.J., Wright, J., Pfeifer, M., Spannagl, M., Martis, M.M., Mascher, M., Chapman, J., Poland, J.A., Scholz, U., Barry, K., Waugh, R., Rokhsar, D.S., Muehlbauer, G.J., Stein, N., Gundlach, H., Zytnicki, M., Jamilloux, V., Quesneville, H., Wicker, T., Faccioli, P., Colaiacovo, M., Stanca, A.M., Budak, H., Cattivelli, L., Glover, N., Pingault, L., Paux, E., Sharma, S., Appels, R., Bellgard, M., Chapman, B., Nussbaumer, T., Bader, K.C., Rimbert, H., Wang, S., Knox, R., Kilian, A., Alaux, M., Alfama, F., Couderc, L., Guilhot, N., Viseux, C., Loaec, M., Keller, B., Praud, S., 2014. A chromosome-based draft sequence of the hexaploid bread wheat (Triticum aestivum) genome. Science 80(345), 1251788-1251788. doi:10.1126/science. 1251788.

McCarthy, F.M., Gresham, C.R., Buza, T.J., Chouvarine, P., Pillai, L.R., Kumar, R., Ozkan, S., Wang, H., Manda, P., Arick, T., Bridges, S.M., Burgess, S.C., 2011. AgBase: supporting functional modeling in agricultural organisms. Nucleic Acids Res. 39, D497-D506. doi:10.1093/nar /gkq1115

McCarthy, F.M., Wang, N., Magee, G.B., Nanduri, B., Lawrence, M.L., Camon, E.B., Barrell, D.G., Hill, D.P., Dolan, M.E., Williams, W.P., Luthe, D.S., Bridges, S.M., Burgess, S.C., 2006. AgBase: a functional genomics resource for agriculture. BMC Genomics. doi:10.1186/1471-2164-7-229

Moriyama, E.N., Strope, P.K., Opiyo, S.O., Chen, Z., Jones, A.M., 2006. Mining the Arabidopsis thaliana genome for highly-divergent seven transmembrane receptors. Genome Biol. 7, R96. doi:10.1186/gb-2006-7-10-r96

Motamayor, J.C., Mockaitis, K., Schmutz, J., Haiminen, N., III, D., Cornejo, O., Findley, S.D., Zheng, P., Utro, F., Royaert, S., Saski, C., Jenkins, J., Podicheti, R., Zhao, M., Scheffler, B.E., Stack, J.C., Feltus, F.A., Mustiga, G.M., Amores, F., Phillips, W., Marelli, J., May, G.D., Shapiro, H., Ma, J., Bustamante, C.D., Schnell, R.J., Main, D., Gilbert, D., Parida, L., Kuhn, D.N., 2013. The genome sequence of the most widely cultivated cacao type and its use to identify candidate genes regulating pod color. Genome Biol. 14, r53. doi:10.1186/gb-2013-14-6-r53.

Ouyang, S., Zhu, W., Hamilton, J., Lin, H., Campbell, M., Childs, K., Thibaud-Nissen, F., Malek, R.L., Lee, Y., Zheng, L., Orvis, J., Haas, B., Wortman, J., Buell, R.C., 2007. The TIGR Rice Genome Annotation Resource: Improvements and new features. Nucleic Acids Res. 35, 8-11. doi:10.1093/nar/gk1976.
Pandey, S., Assmann, S.M., 2004. The Arabidopsis putative G protein-coupled receptor GCR1 interacts with the $G$ protein alpha subunit GPA1 and regulates abscisic acid signaling. Plant Cell 16, 1616-32. doi:10.1105/tpc.020321

Pandey, S., Nelson, D.C., Assmann, S.M., 2009. Two Novel GPCR-Type G Proteins Are Abscisic Acid Receptors in Arabidopsis. Cell 136, 136-148. doi:10.1016/j.cell. 2008.12.026

Park, S.-Y., Fung, P., Nishimura, N., Jensen, D.R., Fujii, H., Zhao, Y., Lumba, S., Santiago, J., Rodrigues, A., Chow, T. -f. F., Alfred, S.E., Bonetta, D., Finkelstein, R., Provart, N.J., Desveaux, D., Rodriguez, P.L., McCourt, P., Zhu, J.K., Schroeder, J.I., Volkman, B.F., Cutler, S.R., 2009. Abscisic Acid Inhibits Type 2C Protein Phosphatases via the PYR/PYL Family of START Proteins. Science. doi:10.1126/science.1173041

Peng, Z.-L., Yang, J.-Y., Chen, X., 2010. An improved classification of G-protein-coupled receptors using sequence-derived features. BMC Bioinformatics 11, 420. doi:10.1186/1471-2105-11-420.

Petersen, T.N., Brunak, S., von Heijne, G., Nielsen, H., 2011. SignalP 4.0: discriminating signal peptides from transmembrane regions. Nat. Methods 8, 785-786. doi:10.1038/nmeth.1701.

Plakidou-Dymock, S., Dymock, D., Hooley, R., 1998. A higher plant seven-transmembrane receptor that influences sensitivity to cytokinins. Curr. Biol. 8, 315-24. doi:S0960-9822(98)70131-9 [pii]

Prochnik, S., Marri, P.R., Desany, B., Rabinowicz, P.D., Kodira, C., Mohiuddin, M., Rodriguez, F., Fauquet, C., Tohme, J., Harkins, T., Rokhsar, D.S., Rounsley, S., 2012. The Cassava Genome: Current Progress, Future Directions. Trop. Plant Biol. 5, 88-94. doi:10.1007/ s12042-011-9088-z

Sato, S., Tabata, S., Hirakawa, H., Asamizu, E., Shirasawa, K., Isobe, S., Kaneko, T., Nakamura, Y., Shibata, D., Aoki, K., Egholm, M., Knight, J., Bogden, R., Li, C., Shuang, Y., Xu, X., Pan, S., Cheng, S., Liu, X., Ren, Y., Wang, J., Albiero, A., Dal Pero, F., Todesco, S., Van Eck, J., Buels, R.M., Bombarely, A., Gosselin, J.R., Huang, M., Leto, J.A., Menda, N., Strickler, S., Mao, L., Gao, S., Tecle, I.Y., York, T., Zheng, Y., Vrebalov, J.T., Lee, J., Zhong, S., Mueller, L.A., Stiekema, W.J., Ribeca, P., Alioto, T., Yang, W., Huang, S., Du, Y., Zhang, Z., Gao, J., Guo, Y., Wang, X., Li, Y., He, J., Li, C., Cheng, Z., Zuo, J., Ren, J., Zhao, J., Yan, L., Jiang, H., Wang, B., Li, H., Li, Z., Fu, F., Chen, B., Han, B., Feng, Q., Fan, D., Wang, Y., Ling, H., Xue, Y., Ware, D., Richard McCombie, W., Lippman, Z.B., Chia, J.-M., Jiang, K., Pasternak, S., Gelley, L., Kramer, M., Anderson, L.K., Chang, S.-B., Royer, S.M., Shearer, L.A., Stack, S.M., Rose, J.K.C., Xu, Y., Eannetta, N., Matas, A.J., McQuinn, R., Tanksley, S.D., Camara, F., Guigó, R., Rombauts, S., Fawcett, J., Van de Peer, Y., Zamir, D., Liang, C., Spannagl, M., Gundlach, H., Bruggmann, R., Mayer, K., Jia, Z., Zhang, J., Ye, Z., Bishop, G.J., Butcher, S., Lopez-Cobollo, R., Buchan, D., Filippis, I., Abbott, J., Dixit, R., Singh, M., 
Singh, A., Kumar Pal, J., Pandit, A., Kumar Singh, P., Kumar Mahato, A., Dogra, V., Gaikwad, K., Raj Sharma, T., Mohapatra, T., Kumar Singh, N., Causse, M., Rothan, C., Schiex, T., Noirot, C., Bellec, A., Klopp, C., Delalande, C., Berges, H., Mariette, J., Frasse, P., Vautrin, S., Zouine, M., Latché, A., Rousseau, C., Regad, F., Pech, J.-C., Philippot, M., Bouzayen, M., Pericard, P., Osorio, S., Fernandez del Carmen, A., Monforte, A., Granell, A., Fernandez-Muñoz, R., Conte, M., Lichtenstein, G., Carrari, F., De Bellis, G., Fuligni, F., Peano, C., Grandillo, S., Termolino, P., Pietrella, M., Fantini, E., Falcone, G., Fiore, A., Giuliano, G., Lopez, L., Facella, P., Perrotta, G., Daddiego, L., Bryan, G., Orozco, M., Pastor, X., Torrents, D., van Schriek, M.G.M., Feron, R.M.C., van Oeveren, J., de Heer, P., DaPonte, L., Jacobs-Oomen, S., Cariaso, M., Prins, M., van Eijk, M.J.T., Janssen, A., van Haaren, M.J.J., Jo, S.-H., Kim, J., Kwon, S.-Y., Kim, S., Koo, D.H., Lee, S., Hur, C.-G., Clouser, C., Rico, A., Hallab, A., Gebhardt, C., Klee, K., Jöcker, A., Warfsmann, J., Göbel, U., Kawamura, S., Yano, K., Sherman, J.D., Fukuoka, H., Negoro, S., Bhutty, S., Chowdhury, P., Chattopadhyay, D., Datema, E., Smit, S., Schijlen, E.G.W.M., van de Belt, J., van Haarst, J.C., Peters, S.A., van Staveren, M.J., Henkens, M.H.C., Mooyman, P.J.W., Hesselink, T., van Ham, R.C.H.J., Jiang, G., Droege, M., Choi, D., Kang, B.C., Dong Kim, B., Park, M., Kim, S., Yeom, S.-I., Lee, Y.-H., Choi, Y.-D., Li, G., Gao, J., Liu, Y., Huang, S., Fernandez-Pedrosa, V., Collado, C., Zuñiga, S., Wang, G., Cade, R., Dietrich, R.A., Rogers, J., Knapp, S., Fei, Z., White, R.A., Thannhauser, T.W., Giovannoni, J.J., Angel Botella, M., Gilbert, L., Gonzalez, R., Luis Goicoechea, J., Yu, Y., Kudrna, D., Collura, K., Wissotski, M., Wing, R., Schoof, H., Meyers, B.C., Bala Gurazada, A., Green, P.J., Mathur, S., Vyas, S., Solanke, A.U., Kumar, R., Gupta, V., Sharma, A.K., Khurana, P., Khurana, J.P., Tyagi, A.K., Dalmay, T., Mohorianu, I., Walts, B., Chamala, S., Brad Barbazuk, W., Li, J., Guo, H., Lee, T.H., Wang, Y., Zhang, D., Paterson, A.H., Wang, X., Tang, H., Barone, A., Luisa Chiusano, M., Raffaella Ercolano, M., D’Agostino, N., Di Filippo, M., Traini, A., Sanseverino, W., Frusciante, L., Seymour, G.B., Elharam, M., Fu, Y., Hua, A., Kenton, S., Lewis, J., Lin, S., Najar, F., Lai, H., Qin, B., Qu, C., Shi, R., White, D., White, J., Xing, Y., Yang, K., Yi, J., Yao, Z., Zhou, L., Roe, B.A., Vezzi, A., D’Angelo, M., Zimbello, R., Schiavon, R., Caniato, E., Rigobello, C., Campagna, D., Vitulo, N., Valle, G., Nelson, D.R., De Paoli, E., Szinay, D., de Jong, H.H., Bai, Y., Visser, R.G.F., Klein Lankhorst, R.M., Beasley, H., McLaren, K., Nicholson, C., Riddle, C., Gianese, G., Sato, S., Tabata, S., Mueller, L.A., Huang, S., Du, Y., Li, C., Cheng, Z., Zuo, J., Han, B., Wang, Y., Ling, H., Xue, Y., Ware, D., Richard McCombie, W., Lippman, Z.B., Stack, S.M., Tanksley, S.D., Van de Peer, Y., Mayer, K., Bishop, G.J., Butcher, S., Kumar Singh, N., Schiex, T., Bouzayen, M., Granell, A., Carrari, F., De Bellis, G., Giuliano, G., Bryan, G., van Eijk, M.J.T., Fukuoka, H., Chattopadhyay, D., van Ham, R.C.H.J.,
Choi, D., Rogers, J., Fei, Z., Giovannoni, J.J., Wing, R., Schoof, H., Meyers, B.C., Khurana, J.P., Tyagi, A.K., Dalmay, T., Paterson, A.H., Wang, X., Frusciante, L., Seymour, G.B., Roe, B.A., Valle, G., de Jong, H.H., Klein Lankhorst, R.M., 2012. The tomato genome sequence provides insights into fleshy fruit evolution. Nature 485 , 635-641. doi:10.1038/nature11119.

Schmutz, J., Cannon, S.B., Schlueter, J., Ma, J., Mitros, T., Nelson, W., Hyten, D.L., Song, Q., Thelen, J.J., Cheng, J., $\mathrm{Xu}$, D., Hellsten, U., May, G.D., Yu, Y., Sakurai, T., Umezawa, T., Bhattacharyya, M.K., Sandhu, D., Valliyodan, B., Lindquist, E., Peto, M., Grant, D., Shu, S., Goodstein, D., Barry, K., Futrell-Griggs, M., Abernathy, B., Du, J., Tian, Z., Zhu, L., Gill, N., Joshi, T., Libault, M., Sethuraman, A., Zhang, X.-C., Shinozaki, K., Nguyen, H.T., Wing, R.A., Cregan, P., Specht, J., Grimwood, J., Rokhsar, D., Stacey, G., Shoemaker, R.C., Jackson, S.A., 2010. Genome sequence of the palaeopolyploid soybean. Nature 463, 178-183. doi:10.1038/nature08670.

Schmutz, J., McClean, P.E., Mamidi, S., Wu, G.A., Cannon, S.B., Grimwood, J., Jenkins, J., Shu, S., Song, Q., Chavarro, C., Torres-Torres, M., Geffroy, V., Moghaddam, S.M., Gao, D., Abernathy, B., Barry, K., Blair, M., Brick, M.A., Chovatia, M., Gepts, P., Goodstein, D.M., Gonzales, M., Hellsten, U., Hyten, D.L., Jia, G., Kelly, J.D., Kudrna, D., Lee, R., Richard, M.M.S., Miklas, P.N., Osorno, J.M., Rodrigues, J., Thareau, V., Urrea, C.A., Wang, M., Yu, Y., Zhang, M., Wing, R.A., Cregan, P.B., Rokhsar, D.S., Jackson, S.A., 2014. A reference genome for common bean and genome-wide analysis of dual domestications. Nat. Genet. 46, 707-713. doi:10.1038/ng.300.

Schnable, P.S., Ware, D., Fulton, R.S., Stein, J.C., Wei, F., Pasternak, S., Liang, C., Zhang, J., Fulton, L., Graves, T.A., Minx, P., Reily, A.D., Courtney, L., Kruchowski, S.S., Tomlinson, C., Strong, C., Delehaunty, K., Fronick, C., Courtney, B., Rock, S.M., Belter, E., Du, F., Kim, K., Abbott, R.M., Cotton, M., Levy, A., Marchetto, P., Ochoa, K., Jackson, S.M., Gillam, B., Chen, W., Yan, L., Higginbotham, J., Cardenas, M., Waligorski, J., Applebaum, E., Phelps, L., Falcone, J., Kanchi, K., Thane, T., Scimone, A., Thane, N., Henke, J., Wang, T., Ruppert, J., Shah, N., Rotter, K., Hodges, J., Ingenthron, E., Cordes, M., Kohlberg, S., Sgro, J., Delgado, B., Mead, K., Chinwalla, A., Leonard, S., Crouse, K., Collura, K., Kudrna, D., Currie, J., He, R., Angelova, A., Rajasekar, S., Mueller, T., Lomeli, R., Scara, G., Ko, A., Delaney, K., Wissotski, M., Lopez, G., Campos, D., Braidotti, M., Ashley, E., Golser, W., Kim, H., Lee, S., Lin, J., Dujmic, Z., Kim, W., Talag, J., Zuccolo, A., Fan, C., Sebastian, A., Kramer, M., Spiegel, L., Nascimento, L., Zutavern, T., Miller, B., Ambroise, C., Muller, S., Spooner, W., Narechania, A., Ren, L., Wei, S., Kumari, S., Faga, B., Levy, M.J., McMahan, L., Van Buren, P., Vaughn, M.W., Ying, K., Yeh, C.-T., Emrich, S.J., Jia, Y., Kalyanaraman, A., Hsia, A.-P., Barbazuk, W.B., Baucom, R.S., Brutnell, 
T.P., Carpita, N.C., Chaparro, C., Chia, J.-M., Deragon, J.-M., Estill, J.C., Fu, Y., Jeddeloh, J.A., Han, Y., Lee, H., Li, P., Lisch, D.R., Liu, S., Liu, Z., Nagel, D.H., McCann, M.C., SanMiguel, P., Myers, A.M., Nettleton, D., Nguyen, J., Penning, B.W., Ponnala, L., Schneider, K.L., Schwartz, D.C., Sharma, A., Soderlund, C., Springer, N.M., Sun, Q., Wang, H., Waterman, M., Westerman, R., Wolfgruber, T.K., Yang, L., Yu, Y., Zhang, L., Zhou, S., Zhu, Q., Bennetzen, J.L., Dawe, R.K., Jiang, J., Jiang, N., Presting, G.G., Wessler, S.R., Aluru, S., Martienssen, R.A., Clifton, S.W., McCombie, W.R., Wing, R.A., Wilson, R.K., 2009. The B73 Maize Genome: Complexity, Diversity, and Dynamics. Science. 80(326), 1112-1115. doi: 10.1126/ science. 1178534.

Shen, Y.-Y., Wang, X.-F.X.-L., Wu, F.-Q., Du, S.-Y., Cao, Z., Shang, Y., Wang, X.-F.X.-L., Peng, C.-C., Yu, X.-C., Zhu, S.-Y., Fan, R.-C., Xu, Y.-H., Zhang, D.-P., 2006. The Mg-chelatase $\mathrm{H}$ subunit is an abscisic acid receptor. Nature 443, 823-826. doi:10.1038/nature05176

Shen, H., Chou, J.J., 2008. MemBrain: Improving the Accuracy of Predicting Transmembrane Helices. PLoS One 3, e2399. doi:10.1371/journal.pone.0002399.

Supek, F., Bošnjak, M., Škunca, N., Šmuc, T., 2011. REVIGO Summarizes and Visualizes Long Lists of Gene Ontology Terms. PLoS One 6, e21800. doi:10.1371/journal.pone. 0021800

Taddese, B., Upton, G.J.G., Bailey, G.R., Jordan, S.R.D., Abdulla, N.Y., Reeves, P.J., Reynolds, C.A., 2014. Do Plants Contain G Protein-Coupled Receptors? PLANT Physiol. 164, 287-307. doi:10.1104/pp.113.228874

Temple, B.R.S., Jones, A.M., 2007. The plant heterotrimeric G-protein complex. Annu. Rev. Plant Biol. 58, 249-266. doi:10.1146/annurev.arplant.58.032806.103827

Theodoropoulou, M., Tsaousis, G., Litou, Z., Bagos, P., Hamodrakas, S., 2013. GPCRpipe: a pipeline for the detection of G-protein coupled receptors in proteomes.

Trusov, Y., Botella, J.R., 2016. Plant G-Proteins Come of Age: Breaking the Bond with Animal Models. Front. Chem. 4, 24. doi:10.3389/fchem.2016.00024

Tuskan, G.A., DiFazio, S., Jansson, S., Bohlmann, J., Grigoriev, I., Hellsten, U., Putnam, N., Ralph, S., Rombauts, S., Salamov, A., Schein, J., Sterck, L., Aerts, A., Bhalerao, R.R., Bhalerao, R.P., Blaudez, D., Boerjan, W., Brun, A., Brunner, A., Busov, V., Campbell, M., Carlson, J., Chalot, M., Chapman, J., Chen, G.-L., Cooper, D., Coutinho, P.M., Couturier, J., Covert, S., Cronk, Q., Cunningham, R., Davis, J., Degroeve, S., Dejardin, A., DePamphilis, C., Detter, J., Dirks, B., Dubchak, I., Duplessis, S., Ehlting, J., Ellis, B., Gendler, K., Goodstein, D., Gribskov, M., Grimwood, J., Groover, A., Gunter, L., Hamberger, B., Heinze, B., Helariutta, Y., Henrissat, B., Holligan, D., Holt, R., Huang, W., IslamFaridi, N., Jones, S., Jones-Rhoades, M., Jorgensen, R., Joshi, C., Kangasjarvi, J., Karlsson, J., Kelleher, C., Kirkpatrick, R., Kirst, M., Kohler, A., Kalluri, U., Larimer, F., Leebens-Mack, J., Leple, J.-C., Locascio, P., Lou, Y., Lucas, S., Martin, F., Montanini, B., Napoli, C.,
Nelson, D.R., Nelson, C., Nieminen, K., Nilsson, O., Pereda, V., Peter, G., Philippe, R., Pilate, G., Poliakov, A., Razumovskaya, J., Richardson, P., Rinaldi, C., Ritland, K., Rouze, P., Ryaboy, D., Schmutz, J., Schrader, J., Segerman, B., Shin, H., Siddiqui, A., Sterky, F., Terry, A., Tsai, C.-J., Uberbacher, E., Unneberg, P., Vahala, J., Wall, K., Wessler, S., Yang, G., Yin, T., Douglas, C., Marra, M., Sandberg, G., Van de Peer, Y., Rokhsar, D., 2006. The Genome of Black Cottonwood, Populus trichocarpa (Torr. \&amp; Gray). Science (80-. ). 313, 1596-1604. doi:10.1126/science.1128691

Tusnády, G.E., Simon, I., 2001. The HMMTOP transmembrane topology prediction server. Bioinformatics 17, 849-850. doi:10.1093/bioinformatics/17.9.849

Urano, D., Jones, A.M., 2013. Round up the usual suspects: A comment on nonexistent plant $\mathrm{G}$ protein-coupled receptors. Plant Physiol. 161, 1097-1102. doi: 10.1104/pp. 112.212324

Urano, D., Jones, A.M., 2014. Heterotrimeric G ProteinCoupled Signaling in Plants. Annu. Rev. Plant Biol. 65, 365-384. doi:10.1146/annurev-arplant-050213-040133.

Viklund, H., Elofsson, A., 2008. OCTOPUS: improving topology prediction by two-track ANN-based preference scores and an extended topological grammar. Bioinformatics 24, 1662-1668. doi:10.1093/ bioinformatics/btn221.

Xu, X., Pan, S., Cheng, S., Zhang, B., Mu, D., Ni, P., Zhang, G., Yang, S., Li, R., Wang, J., Orjeda, G., Guzman, F., Torres, M., Lozano, R., Ponce, O., Martinez, D., De la Cruz, G., Chakrabarti, S.K., Patil, V.U., Skryabin, K.G., Kuznetsov, B.B., Ravin, N. V., Kolganova, T. V., Beletsky, A. V., Mardanov, A. V., Di Genova, A., Bolser, D.M., Martin, D.M.A., Li, G., Yang, Y., Kuang, H., Hu, Q., Xiong, X., Bishop, G.J., Sagredo, B., Mejía, N., Zagorski, W., Gromadka, R., Gawor, J., Szczesny, P., Huang, S., Zhang, Z., Liang, C., He, J., Li, Y., He, Y., Xu, J., Zhang, Y., Xie, B., Du, Y., Qu, D., Bonierbale, M., Ghislain, M., del Rosario Herrera, M., Giuliano, G., Pietrella, M., Perrotta, G., Facella, P., O’Brien, K., Feingold, S.E., Barreiro, L.E., Massa, G.A., Diambra, L., Whitty, B.R., Vaillancourt, B., Lin, H., Massa, A.N., Geoffroy, M., Lundback, S., DellaPenna, D., Robin Buell, C., Sharma, S.K., Marshall, D.F., Waugh, R., Bryan, G.J., Destefanis, M., Nagy, I., Milbourne, D., Thomson, S.J., Fiers, M., Jacobs, J.M.E., Nielsen, K.L., Sønderkær, M., Iovene, M., Torres, G.A., Jiang, J., Veilleux, R.E., Bachem, C.W.B., de Boer, J., Borm, T., Kloosterman, B., van Eck, H., Datema, E., te Lintel Hekkert, B., Goverse, A., van Ham, R.C.H.J., Visser, R.G.F., 2011. Genome sequence and analysis of the tuber crop potato. Nature. 475, 189-195. doi:10.1038/nature10158.

Yadav, D.K., Islam, S.M.S., Tuteja, N., 2012. Rice heterotrimeric G-protein gamma subunits (RGG1 and RGG2) are differentially regulated under abiotic stress. Plant Signal. Behav. 7, 733-740. doi:10.4161/psb.20356

Yadav, D.K., Tuteja, N., 2011. Rice G-protein coupled receptor (GPCR): in silico analysis and transcription 
regulation under abiotic stress. Plant Signal. Behav. 6, 1079-86. doi:10.4161/psb.6.8.15771

Yarnitzky, T., Levit, A., Niv, M.Y., 2010. Homology modeling of G-protein-coupled receptors with X-ray structures on the rise 13, 317-325.

Young, N.D., Debellé, F., Oldroyd, G.E.D., Geurts, R., Cannon, S.B., Udvardi, M.K., Benedito, V.A., Mayer, K.F.X., Gouzy, J., Schoof, H., Van de Peer, Y., Proost, S., Cook, D.R., Meyers, B.C., Spannagl, M., Cheung, F., De Mita, S., Krishnakumar, V., Gundlach, H., Zhou, S., Mudge, J., Bharti, A.K., Murray, J.D., Naoumkina, M.A., Rosen, B., Silverstein, K.A.T., Tang, H., Rombauts, S., Zhao, P.X., Zhou, P., Barbe, V., Bardou, P., Bechner, M., Bellec, A., Berger, A., Bergès, H., Bidwell, S., Bisseling, T., Choisne, N., Couloux, A., Denny, R., Deshpande, S., Dai, X., Doyle, J.J., Dudez, A.-M., Farmer, A.D., Fouteau, S., Franken, C., Gibelin, C., Gish, J., Goldstein, S., González, A.J., Green, P.J., Hallab, A., Hartog, M., Hua, A., Humphray, S.J., Jeong, D.-H., Jing, Y., Jöcker, A.,
Kenton, S.M., Kim, D.-J., Klee, K., Lai, H., Lang, C., Lin, S., Macmil, S.L., Magdelenat, G., Matthews, L., McCorrison, J., Monaghan, E.L., Mun, J.-H., Najar, F.Z., Nicholson, C., Noirot, C., O’Bleness, M., Paule, C.R., Poulain, J., Prion, F., Qin, B., Qu, C., Retzel, E.F., Riddle, C., Sallet, E., Samain, S., Samson, N., Sanders, I., Saurat, O., Scarpelli, C., Schiex, T., Segurens, B., Severin, A.J., Sherrier, D.J., Shi, R., Sims, S., Singer, S.R., Sinharoy, S., Sterck, L., Viollet, A., Wang, B.-B., Wang, K., Wang, M., Wang, X., Warfsmann, J., Weissenbach, J., White, D.D., White, J.D., Wiley, G.B., Wincker, P., Xing, Y., Yang, L., Yao, Z., Ying, F., Zhai, J., Zhou, L., Zuber, A., Dénarié, J., Dixon, R.A., May, G.D., Schwartz, D.C., Rogers, J., Quétier, F., Town, C.D., Roe, B.A., 2011. The Medicago genome provides insight into the evolution of rhizobial symbioses. Nature. doi:10.1038/nature10625

Zhang, Z., 2012. A brief review on the evolution of GPCR: conservation and diversification. Open J. Genet. 02, 1117. doi:10.4236/ojgen.2012.24B003

\section{How to cite this article:}

Amora, D. X., Bresso, E., Togawa, R.C., Grynberg, P., Maigret, B., Martins, N. F., 2016. Prediction of G protein coupled receptors from plant genomes. Int. J. Curr. Res. Biosci. Plant Biol. 3(11), 92-107.

doi: http://dx.doi.org/10.20546/ijcrbp.2016.311.014 